\title{
Upliving - Student Accommodation
}

\author{
By
}

\section{Joshua Roberts}

A 120-point thesis

submitted to the Victoria University of Wellington in partial fulfilment of the requirements for the degree of Master of Architecture (Professional)

Victoria University of Wellington

School of Architecture 
Upliving - Student Accommodation 


\begin{abstract}
This research proposal looks into the future at an increase in student population, an increase in basic living costs, the looming issues with densification of Wellington City, and its development to the transport infrastructure. The project aims to create accommodation for students going through university while providing a simple and cohesive mode of transport linking the CBD. The biggest motivator for Upliving is Wellington's great potential for infill buildings in spaces such as cracks between buildings; above roads; atop buildings; underutilised areas within an urban context; temporarily empty sites awaiting future development; and car parks (particularly with the development of transport infrastructure, eliminating the need for as many vehicles within the city). The development would be funded by universities in collaboration with the city to help compensate for the rising education costs and rising living costs. It will provide better transport within the city, opening up more potential for development with less infrastructure to facilitate the currently high vehicle usage. The goals of the architecture are to accommodate students, maintain a minimal building footprint, effectively use circulation spaces to minimise an inclination to damage of property, create flexible spaces, maintain a simple structure for rapid construction, provide active communal spaces, establish connections to university campuses, generally link the Wellington's $\mathrm{CBD}$, use underutilised spaces, and maintain a contemporary identity that blends into the urban context. There are many aspects involved in this research portfolio, including the notion of research by design through the use of an in-depth iterative process, precedent investigations, client/occupant research, detailed design explorations of large and small scales, an outcome, and a critical reflection highlighting possible changes and a direction for further development.
\end{abstract}




\section{Preface}

As part of fourth-year studies a paper was completed that has then formed the basis and inspiration for this research portfolio. As the author of this project, it was possible to critique and determine areas for improvement and growth leading to the project undertaken. The project, titled 'The Halfway Neighbourhood', consisted of the research and design for a communal accommodation space for homeless people, which aimed to rejuvenate Farmers Lane in Wellington city. A strong passion for designing for homeless people was established from the process undertaken for 'The Halfway Neighbourhood' (with a timeframe from mid to late 2016). Because of this passion, the fourth-year project led to the research and preliminary design for this research portfolio. Beginning the research portfolio with the end of a previous project had its challenges. Many roadblocks caused a change in design motivation and ultimately a change in the project. The research revealed a large amount of possibility in regards to the direction that the project could go, so the decision was made to take a much more direct approach, proposing that in the near future the student population could become homeless. This topic became instantly more relevant, making it much easier to be passionate about the project.

The research question began as, 'How can the space that a homeless person inhabits be transformed positively, without drastically altering what the person is used to while providing a healthy, safe and beautiful environment for all?'. By the end of the project, the research question had developed into, 'How can student accommodation help to combat Wellington City's struggle, with limited urban space and the need for urban development?' This shows the dramatic transition from the beginning to the end of the project, however, remains close to the original motivation. 


\section{Contents}

Title Page

\begin{tabular}{lll}
\hline Abstract & iii \\
\hline Preface & iv \\
\hline Contents & $\mathbf{v}$ \\
\hline Chapter 1 - Introduction & 1 & $\mathbf{1}$ \\
\hline I - Problem Statement & 1 & \\
II - Research Question & 1 & \\
III - Research Aims and Objectives & 2 & \\
IV - Design Methods and Process & 4 & \\
V - Methodology & 9 & \\
VI - Design Scope & 9
\end{tabular}

\section{Chapter 2 - Context Analysis}

I - Initial Site Research 10

II - Site Speculation 11

III - Site Experimentation 11

IV - Site Analysis 12

V - Site Validation 13

\section{Chapter 3 - Programme Analysis}

I - Client Investigation 14

II - Programmatic Requirements 14

III - Programme Separation 16

IV - Programme Experimentation 16

V - Project Scale

18

\section{Chapter 4 - Literature Review}

I - Rene Descartes Rational Method 19

II - Cynicism in Ancient Greece 19

III - Metabolist Architecture 20

IV - Literature Discussing Homelessness

20

\section{Chapter 5 - Project Review}

I - Key Precedent Analysis

II - Precedent Design Comparison 25

\section{Chapter 6 - Preliminary Design}




\begin{tabular}{cll}
\hline II - Abstract Experimentation & 29 \\
\hline III - Controlled Experimentation & 30 & $\mathbf{3 1}$ \\
\hline Chapter 7 - Developing the Design & 31 & \\
\hline I - Design Process & 32 \\
\hline II - Design Experimentation & 35 & \\
\hline III - Detailing the Design & $\mathbf{3 8}$ \\
\hline Chapter 8 - Conclusions and Critical Reflection & $\mathbf{4 0}$ \\
\hline Chapter 9 - Bibliography & 40 & \\
\hline I - Texts & 40 & \\
II - Websites & 41 & \\
III - Figures & & \\
\hline
\end{tabular}




\section{Chapter 1 - Introduction}

\section{I - PROBLEM STATEMENT}

This research portfolio looked into the near future with an increased student population, an increased basic living costs, the densification of Wellington City, and required development to the transport infrastructure. The project aimed to solve these problems by providing accommodation to students that have a minimal footprint provides public transport and best utilises poorly used spaces within the city.

\section{II - RESEARCH QUESTION}

How can student accommodation help to combat Wellington City's struggle, with limited urban space and the need for urban development?

\section{III - RESEARCH AIMS AND OBJECTIVES}

Upliving aimed to accommodate the growing population of students going through university, with increasing housing issues and the need for densification in Wellington City. This projects aimed to achieve its goals by transforming urban spaces with wasted opportunities, as well as providing a unified mode of transport that helps to link the CBD. The goals of the architecture were to: accommodate students, maintain a minimal building footprint, effectively use circulation spaces to minimise damage, create flexible/changeable spaces, maintain a simple structure for rapid construction, provide active communal spaces, establish connections to university campuses, implement a transport system Wellington's CBD, use underutilised spaces, and maintain a contemporary identity that blends into the urban context. The project had a series of aims that defined a successful outcome:

\section{Aims}

- Accommodate students as the population of students in Wellington continues to increase

- Maintain a minimal building footprint in consideration for the inability to expand horizontally

- Minimise circulation to reduce the possibility of damage in communal spaces

- Create flexible spaces that can be utilised differently according to the requirements of the occupant

- Maintain a simple structure for rapid construction that can be used beyond Wellington

- Provide active communal spaces for student interactions

- Establish links between university campuses and other Wellington amenities

- Use spaces that are not effectively utilised, such as cracks between buildings, spaces above roads, spaces atop buildings, etc. 


\section{Objectives}

- Examine and extrapolate the increasing cost of tertiary education and its detriment to students

- Explore through design, an architecture that connects Wellington universities and provides students with a comfortable space to live throughout their studies

- Explore the rejuvenation of space that can be applied to Wellington's urban spaces

- Design iteratively to achieve a resolved solution

- Research case studies to develop an understanding of the most effective student housing programme

- Complete experiments that highlight what a student wants and needs when it comes to everyday life whilst in tertiary education

- Iterative design experiments exploring minimal circulation and maximum occupancy

- Large site analysis to determine the best method and route of a linking transport system

- Iterative design experiments to determine the best locations around the city

There are many site opportunities within wellington, however, challenges arise when attempting to design for all of the different site opportunity typologies. Therefore only one typology has been chosen. After experimenting with different sites, it was found that the space above roads is always going to be an issue and makes up the majority of the wasted spaces within the city. Other spaces would have drastically changed direction and would have made it difficult to stay on the path of mass accommodation for homeless students. The method for the design process for this project allowed a detailed analysis of most design aspects through the use of case studies and extensive iterative design.

\section{IV - DESIGN METHODS AND PROCESS}

Some key authors, designers, and theorists had strong influences on this project including Rene Descartes, Frank Lloyd Wright, Kenzo Tange, Andrew F. Smith, Daniel Quinn, and Silvia Montiglio. Rene Descartes rational method was largely utilised throughout the project, with a division into smaller manageable portions (Descartes, 2004). Visionary architects Frank Lloyd Wright and Kenzo Tange had a large influence in their large scale hypothetical projects, exploring solutions for futuristic conditions. A few key authors (Andrew F. Smith, Daniel Quinn and Silvia Montiglio) were investigated and utilised to contribute to the development of the programme. In 'In Defence of Homelessness' Andrew F. Smith discusses the congregation of homeless people and how spaces to accommodate them should be designed near where they already feel comfortable (Smith, 2013). In Beyond Civilization Daniel Quinn talks about designing for homeless people rather than forcing them into a place that the majority of people deem to be normal (Quinn, 2000). This was valuable as it provided a good initial stance to base the project from. Quinn highlights the fact design should be based on the occupant. In 'Wandering in Ancient Greek Culture' Silvia Montiglio discusses Cynicism and the wisdom and 
freedom of homeless wanderers (Montiglio, 2005). The concept for Upliving uses these principles of 'wandering the streets' by connecting many areas throughout the city, becoming permeable by weaving into the urban environment. Kenzo Tange's project 'A Plan for Tokyo' and Frank Lloyd Wright's project 'Broadacre City' are relevant to the project because they look into the future at solving a problem and also provides mass accommodation (Tange, 2016) (Wright, 2013). 'A Plan for Tokyo' is particularly relevant because of his floating construction that barely impacts the earth below, utilised unused space. This is very exciting and is a major driver for the research portfolio. Another major influence is Daniel Illum Davis' thesis project. His project seems to follow Daniel Quinn's ideas about creating a space that homeless people find comfort within the city, with minimal impact on the environment, blending into with the urban fabric (Illum-Davis, 2012).

The majority of the project process explores the notion of research by design, with an in-depth iterative investigation used in multiple areas throughout the project. Below is a breakdown of the process including a precedent study, a client/occupant study, a detailed design exploration of each building component, and an outcome. The final component is a critical reflection to speculate where the project might be taken in the future. The role of design in this project is to transition from research to an architectural solution, which fills the gap in student accommodation and attempts to solve some of Wellington's housing issues. Design is used to find a better method of transport around the city to help free up dense traffic and the overpopulation of buses in the CBD due to the overlaps in bus routes. Iterative design has been used as a method of research to test different methods of providing the essentials in a space to suit the program at multiple different scales.

The structure of this research portfolio follows a similar structure to the design process, beginning with research and analysis and developing into research by design, finally coming to a conclusion that proposes a new look and direction for the project that can be taken further. Each chapter explicitly describes and justifies my design process throughout the project step by step. 


\section{V - METHODOLOGY}

- Initial Idea

- Inspiration/case studies

- $\quad$ Lit review

- Site exploration

- Project direction

- Idea reconsideration

- Goals and achievements

- Client/occupant study

- Research - case study matrices and comparisons

- $\quad$ Concept idea

- Specific building element breakdown and concept design

- Iterative amenity development

- Iterative dwelling development

- Iterative structure development

- Iterative connection development

- Critical evaluation

- Second design process to unify all separate building elements

- Critical evaluation

- Design consideration

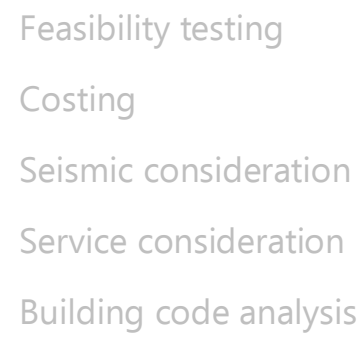

- Further design development

- Critical evaluation

- Final design 


\section{Methodology Summary}

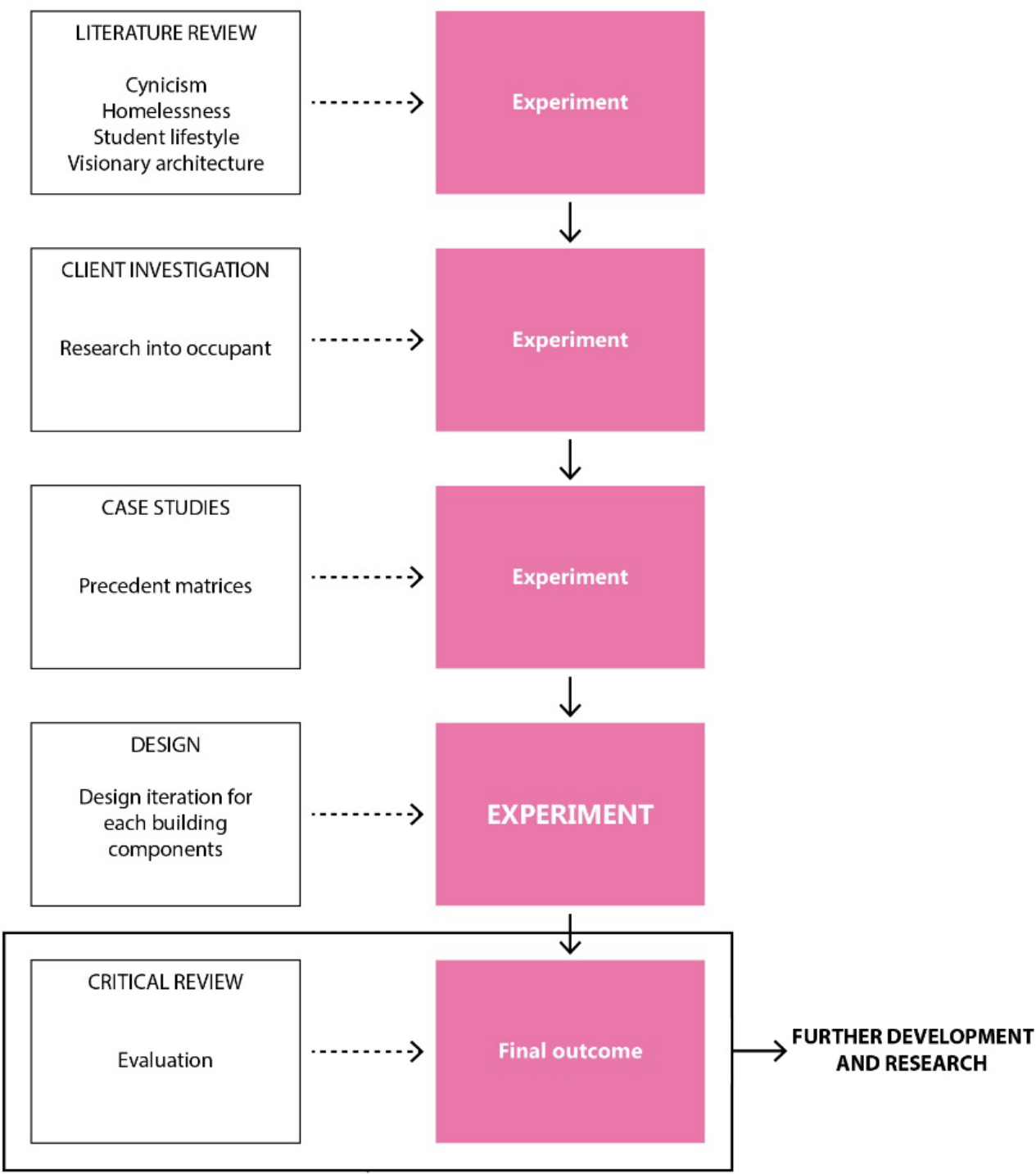

Figure 01. Methodology Diagram 


\section{Iterative Design Process Methodology}

The developed design process methodology was broken down into four more manageable components: The amenities required for living, the dwelling shell to provide shelter, the structure that supports each of the dwellings and the wider city connection.

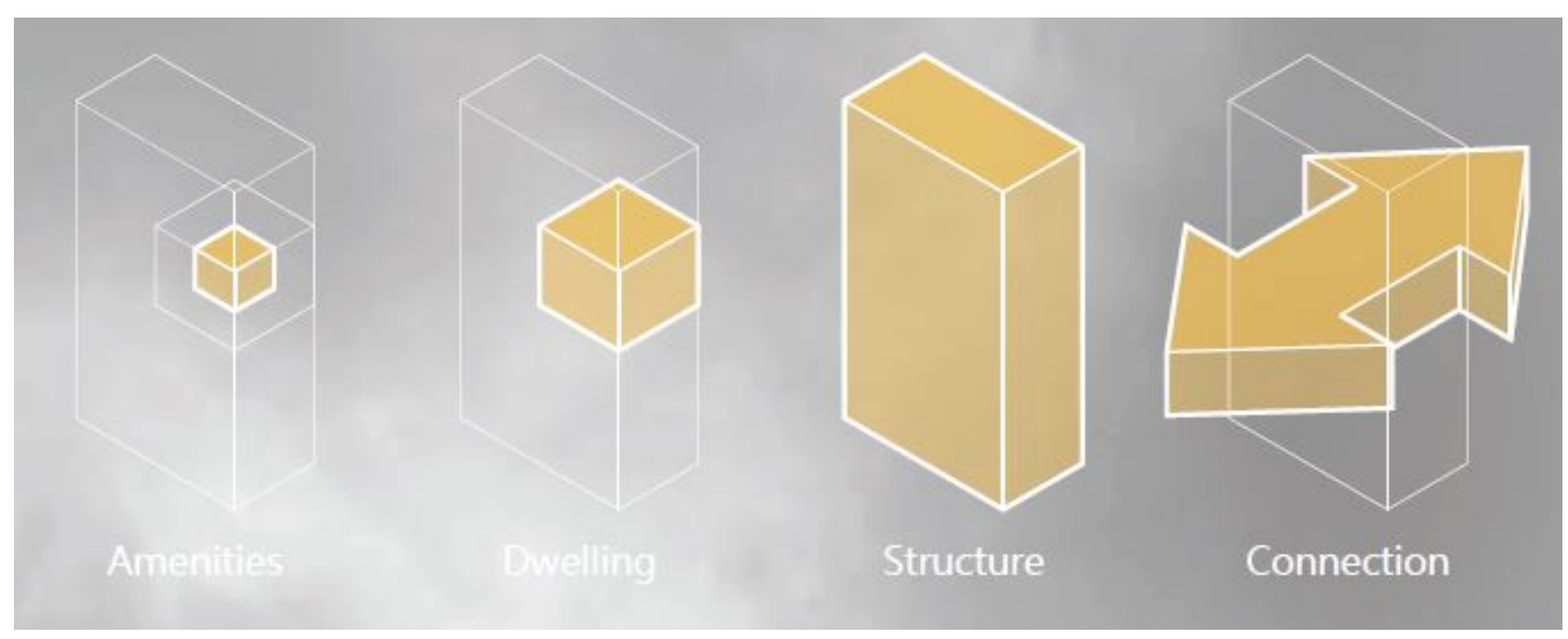

Figure 02. Design Components

\section{Amenity}

- Exploration study of modular design

- Refinement of study to single design through comparisons and iterations

- Modelling explorations - toilet design and overall layout and scale design

- Sketch iterations in plan

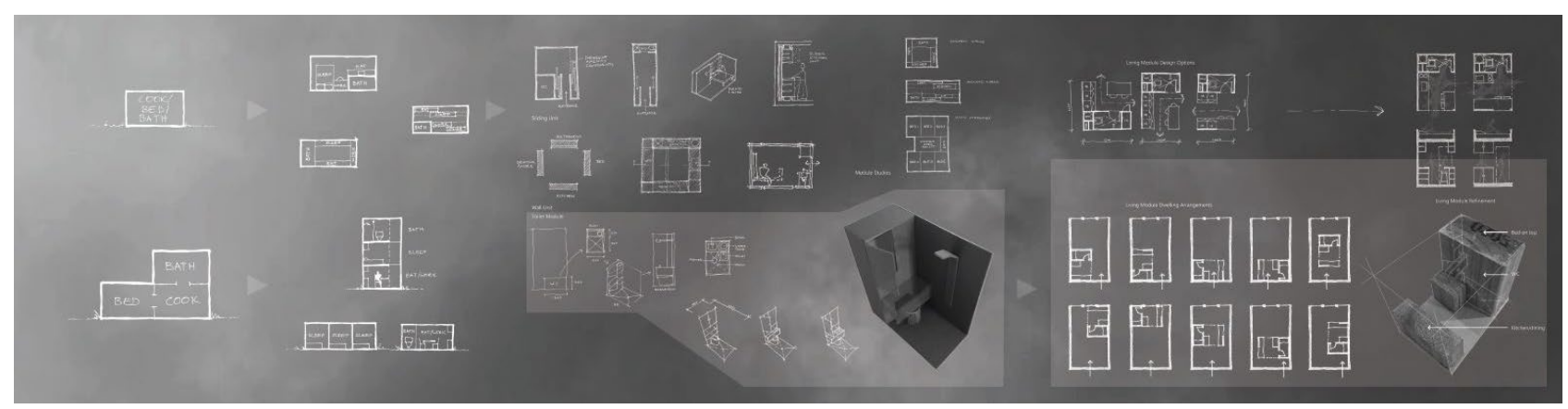

Figure 03. Amenity Concept Process

\section{Dwelling}

- Modelling study exploration - based on site exploration at the beginning

- Dwelling analysis

- Sun exploration

- Circulation exploration

- Dimension study comparison (volume and height relationship)

- Façade customisation exploration (based on dwelling analysis) 
- Structure exploration (based on dwelling analysis)

- Fixings exploration and connection

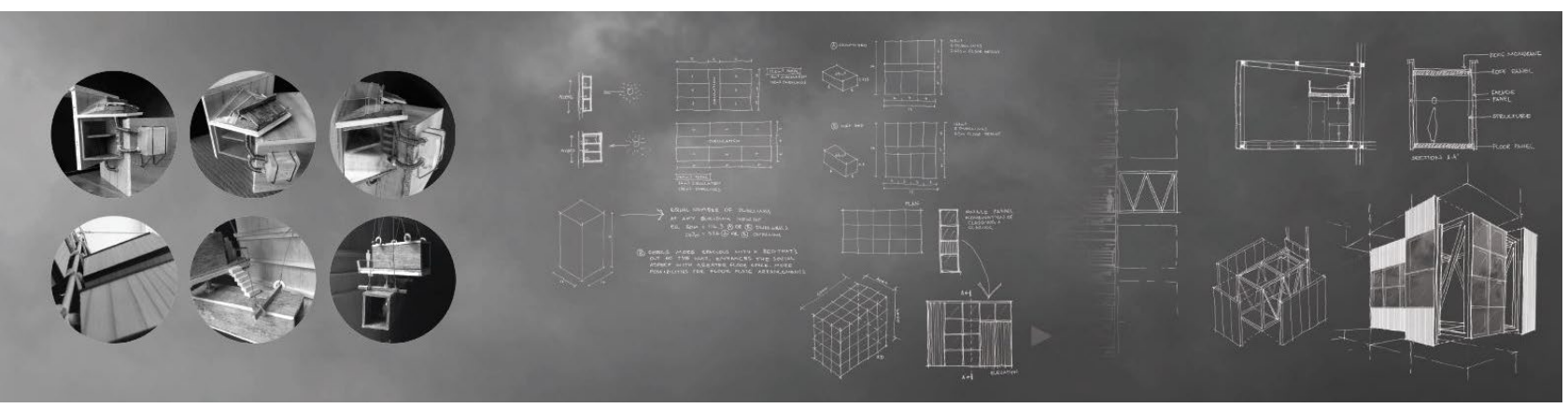

Figure 04. Dwelling Concept Process

\section{Structure}

- Iteration 1

- Explore through sketch, a dwelling cantilevered off a central core,

- Explore self-construction with central crane structure

- Modelling exploration of structure, materiality and planning (particularly the core

- Critical review

- Iteration 2

- Iterative Modelling exploration - vertical circulation only - trying to minimise circulation based on client research (damage to property - in-between spaces)

- Site analysis (again) - the refinement of initial site exploration - changed to spaces above roads to maintain a solid direction and for uniformity of the project.

- Circulation planning concept - through sketch

- Critical review

- Iteration 3

- Exploration of structure above a road and access up to the main floor

- Sketch development from circulation experiment

- Aesthetic consideration of cohesiveness and wrapping a structure that suspends the dwellings (a combination of the previous two structure concepts)

- Modelling exploration of the final concept 


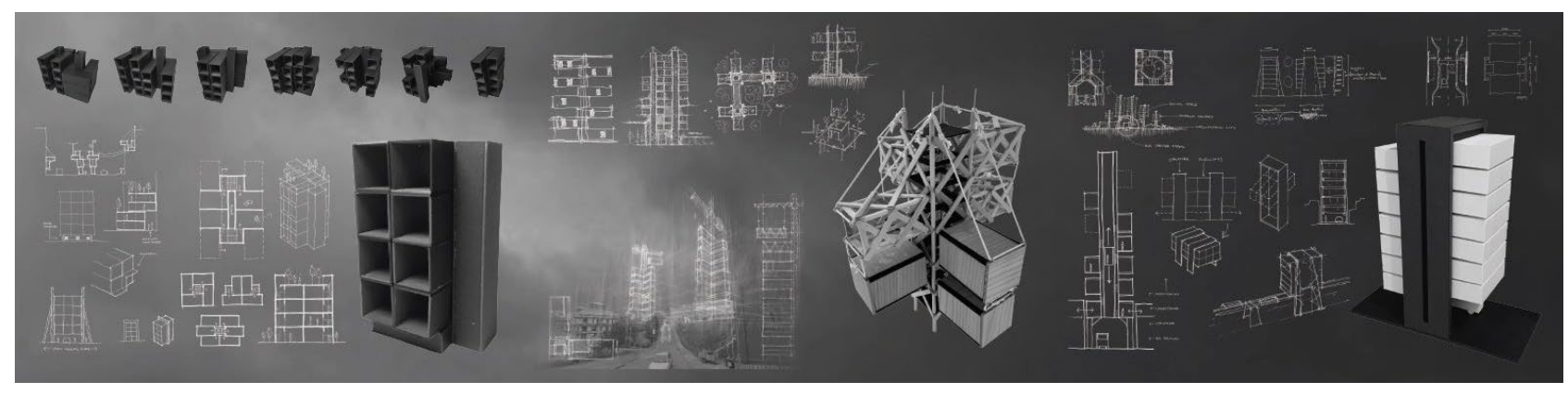

Figure 05. Structure Concept Process

\section{Connection}

- Detailed site research

- Campus locations

- Car park locations

- Wellington amenities

○ Existing bus/transport system analysis

- Proposed division of wellington region into transport precincts and nodes (start a new transport system from scratch)

- Iterative route design and selection of concept route connected with some sort of transport (monorail?)

- Explore the idea of nodes connecting the city

- Addition of minor and major nodes providing accommodation and connection to the city

- Monorail research and exploration through sketch

- Cohesiveness, considering all previous project components aesthetic design of repeating wrapping form

- Monorail connection to building explored through sketch

- Monorail connection to building explored through modelling

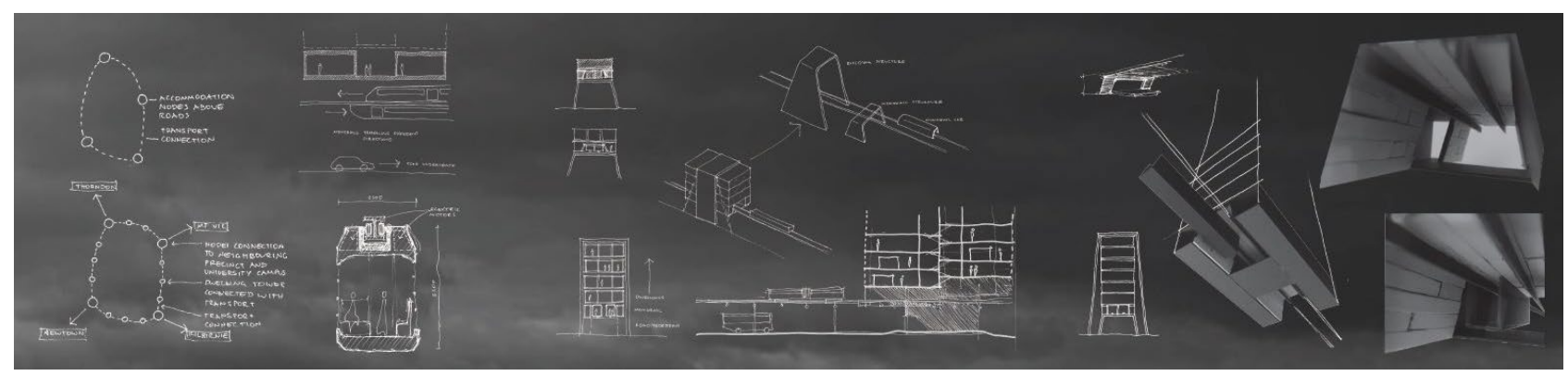

Figure 06. Connection Concept Process

A large portion of methodology (second layer of design consideration) has been set up but removed from this project as due to the nature of this project it was more worthwhile to focus on the research by design element instead of some of the construction parameters. These elements would be explored if the project were 
to be continued. Following the in-depth developed design stage, the project moved onto the final design outcome.

\section{VI - DESIGN SCOPE}

The design scope was to achieve an in part solution to an extrapolated condition of homeless students in a future Wellington City. Limitations include Wellington's current state, it is not set up for further development, as it is in a bowl and cannot expand as a city horizontally, only vertically and more densely. The project is limited in terms of programme and precedent, as the main example of effective student accommodation in wellington are student halls, which is a dense way to live but not always pleasant in terms of location and communal/amenity space.

The scope of the project is very large, so multiple things are not able to be explored thoroughly enough due to the small time frame. Therefore, elements such as finances and costs, and structural and service implications that require engineers have been left out due to the extensive extra work required. The heritage and neighbouring building of the site require much more in-depth analysis than could be produced in the timeframe for this project, without the sacrifice of other components.

As the project is proposed for a future condition, there is great potential, however, it is impossible to estimate the conditions exactly. Therefore many assumptions have been made, which means educated decisions can become very tricky, particularly with how transport works in Wellington. A new transport proposal for the future might have already been done in one way or another, so by the time this project would be implemented it might require alteration to collaborate with the existing, instead of including a transport redevelopment. The project has been designed as a standalone system without a large consideration to its surroundings. Because the project is designed for the future, many different possibilities could occur, causing the building's surroundings to be theoretical at this point. There were many implications with expanding the scope to include all relevant aspects, instead of merely the most important. Students vary in the way that they work and live, so a large challenge arises that a single system or way of life doesn't work for everyone. To solve this multiple solutions should be designed, therefore this project focuses on only the majority to maintain a controlled project extent.

As this is a very small individual project with a very short timeframe ( 9 months), it does not have extensive resources, such as a large design team, only the most relevant aspects can be considered. This converts the process from a real-world example to an experiment/investigation, giving more room for redevelopment and to try new ways of thinking about architecture. The project was completed through this lens providing more freedom from reality and for more speculation and critique of the standard to occur. 


\section{Chapter 2 - Site and Context Analysis}

\section{I - INITIAL IDEAS}

Wellington's urban environment, in its current state, is very dense. This density causes many interesting effects within the city. To begin the context analysis the first step, following the initial decision to design for Wellington City, real-world exploration and analysis of Wellington's 'quirky' spaces was carried out while wandering the city (much like followers of cynicism (Montiglio, 2005), which is discussed in Chapter 4 Literature Review). This exploration brought to light the eclectic mix of poorly used spaces among the city. Most spaces would be considered unbuildable, or not worth the time, however, this research portfolio explores in part how these such spaces could be better utilised to benefit the city. Some of these spaces include cracks between buildings, above roads, atop buildings, underutilised areas within an urban context, temporarily empty sites awaiting future development, and car parks (see figures $07,08,09,10$ and 11). The range of underutilised sites within the city is a large motivator for Upliving.

IMAGE UNAVAILABLE

Figure 07. Cranes on Queens Wharf

IMAGE UNAVAILABLE

Figure 09. Farmers Lane

IMAGE UNAVAILABLE
IMAGE UNAVAILABLE

Figure 08. Car Park on Bond Street
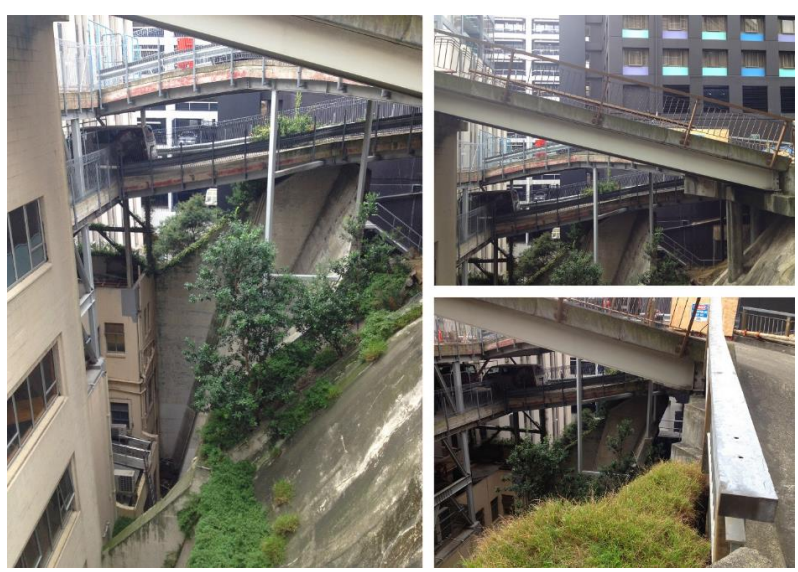

Figure 10. Car Park on The Terrace 


\section{II - SITE SPECULATION}

From the analysis of Wellington City's 'unbuildable' sites, a series of typologies have been recognised.

- Small spaces between buildings

- Rooftops

- $\quad$ Spaces hung from buildings

- Temporarily empty sites awaiting future development

- The airspace above roads and footpaths

- Portable spaces

- Below bridges

- Suspended beneath wellingtons motorway

- In the harbour

- Beneath Wellingtons waterfront

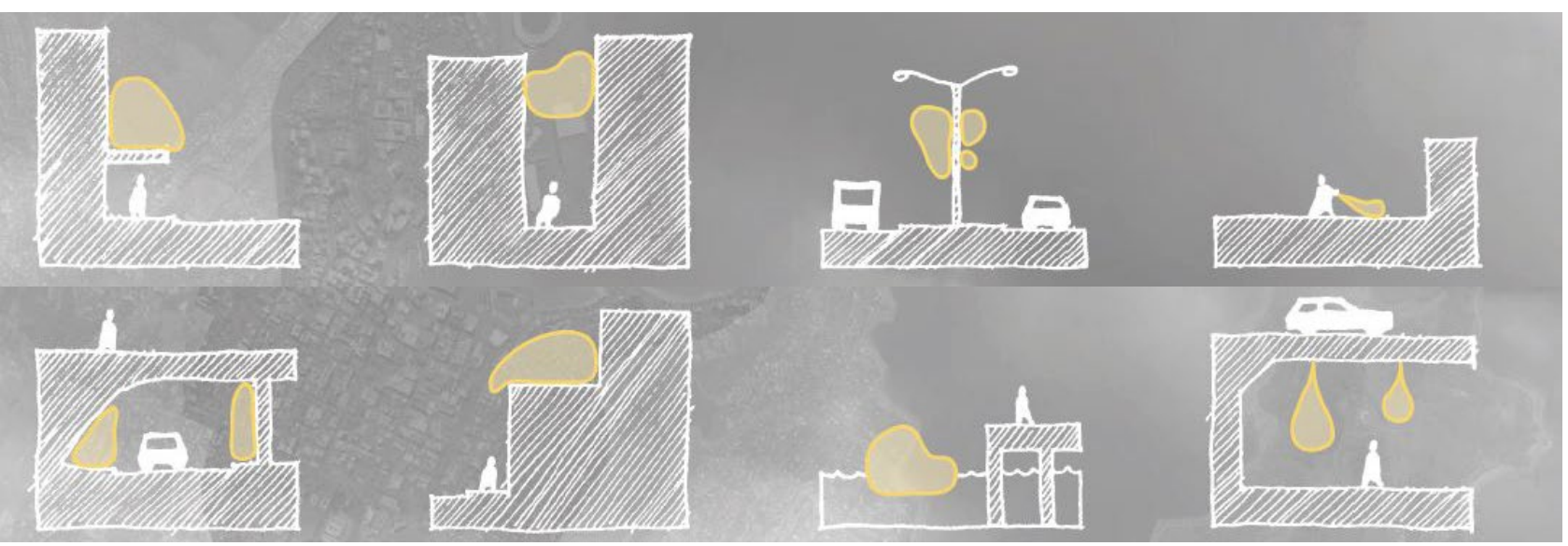

Figure 12. Site Conditions

\section{III - SITE EXPERIMENTATION}

The previously mentioned above site typologies consist of a wide range of shapes, sizes and potential structural elements, as well as location-specific implications of building, such as property laws, building code rules, accessibility and many more. Another obvious issue with the range of sites is that they are all different and it is a large task to form a singular design to suit all sites.
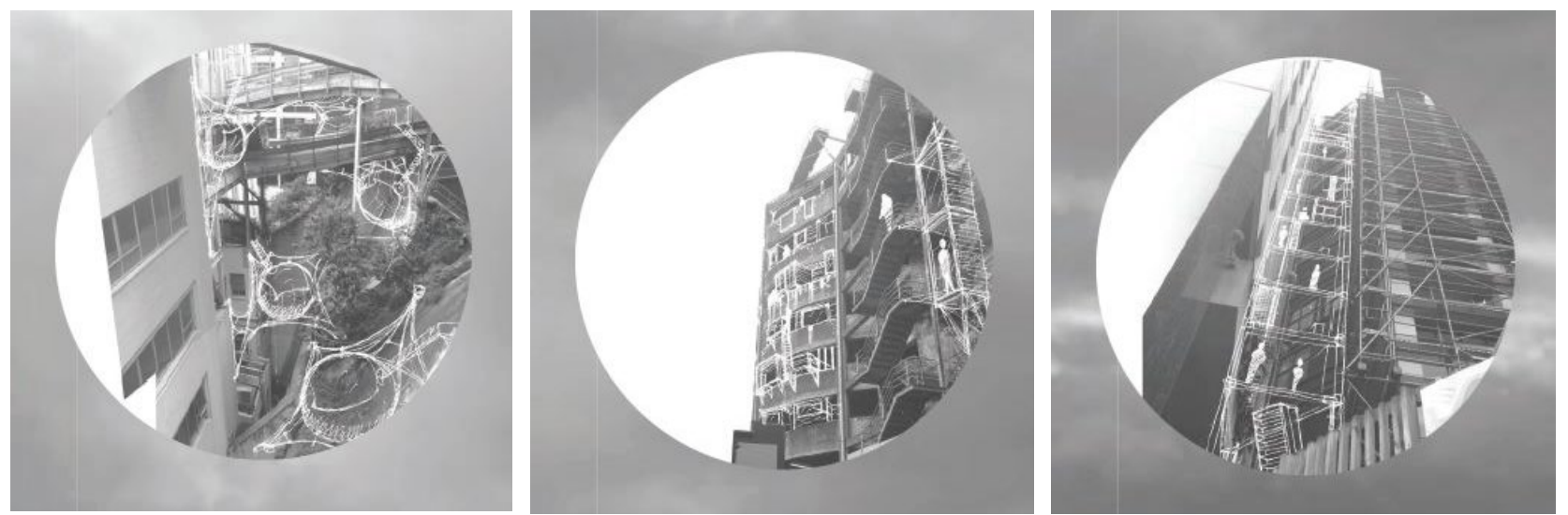

Figure 13. Photo Sketch Experiment 
To arrive at a single site condition, a series of small sketch experiments were carried out to determine a site that would best suit mass accommodation among the city. The experiment consisted of two parts, a series of photos showing what could be considered as wellingtons most underutilised spaces, and subsequently a sketch overlay exercise that highlights the potential of the photographed sites (see figure 13). As the proposed condition, which is a future of homeless students, is quite large, the site needs to facilitate this size with a focus on mass production to be copied throughout the city. There are many issues when it comes to multiple site conditions, particularly the large range in typologies, differentiation in size, and different environmental conditions. This research portfolio attempts to solve one typology of uniformly repeated underutilised space, appearing throughout Wellington, to maintain a more logical method, and therefore outcome, for the project. The project focusses on the airspace above roads, as it was seen to be the site with the most potential and provides a very strong base for the connection aspect, which is discussed further in following chapters.

\section{IV - SITE ANALYSIS}

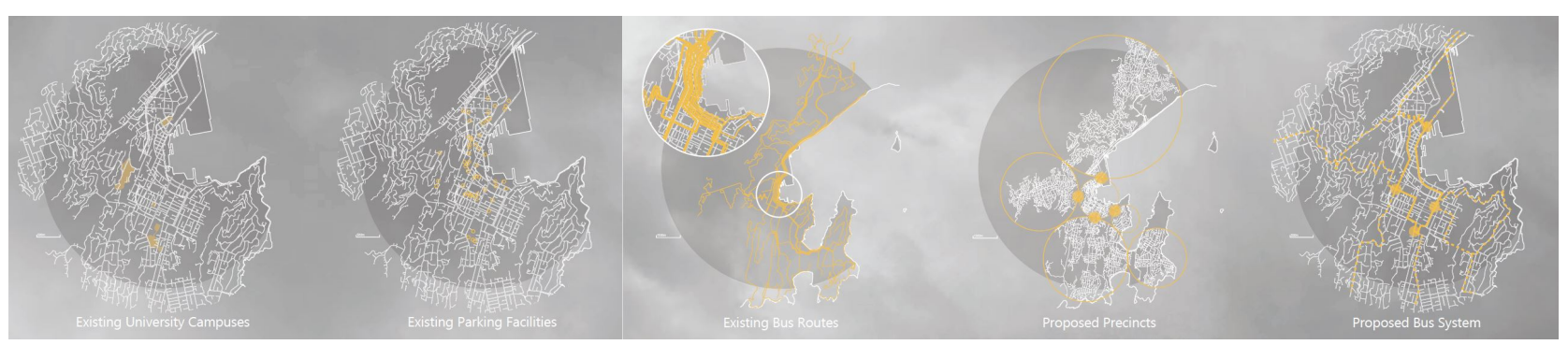

Figure 14. Site and Context Analysis

Following the site experimentation, a brief analysis of Wellington City's CBD was executed. The analysis looks into the context of the $C B D$, including car park spaces and available university spaces that have the potential to be developed. The experiment identified the wasted space around the city, which could be used for development if there was a transport system that could remove the need for car parks within the CBD. An investigation into the existing bus routes within wellington was undertaken to see the existing condition to extrapolate the potential future condition. The transport system was found to have a lot of overlap in bus routes within the city centre, which could begin to be solved with a revised central transport route, removing the clutter, in the form of vehicles and car parks from the streets. The wider Wellington region was divided into a series of precincts, including a central $C B D$ one that connects to outer ones, which aimed to remove the overlap in the existing public transport system. From the selected precincts, a series of nodes were identified as a station or transition points to connect a central route to wider regional routes, presenting an effective route within the CBD. This method of analysis gave a good understanding of how the city currently worked and provided a very strong reason for updating the transport system. Further development would look at the 
route and city nodes and analyse where each connection node would be situated, it would be based on surrounding amenities, surrounding transport, and the road network.

\section{V - SITE VALIDATION}

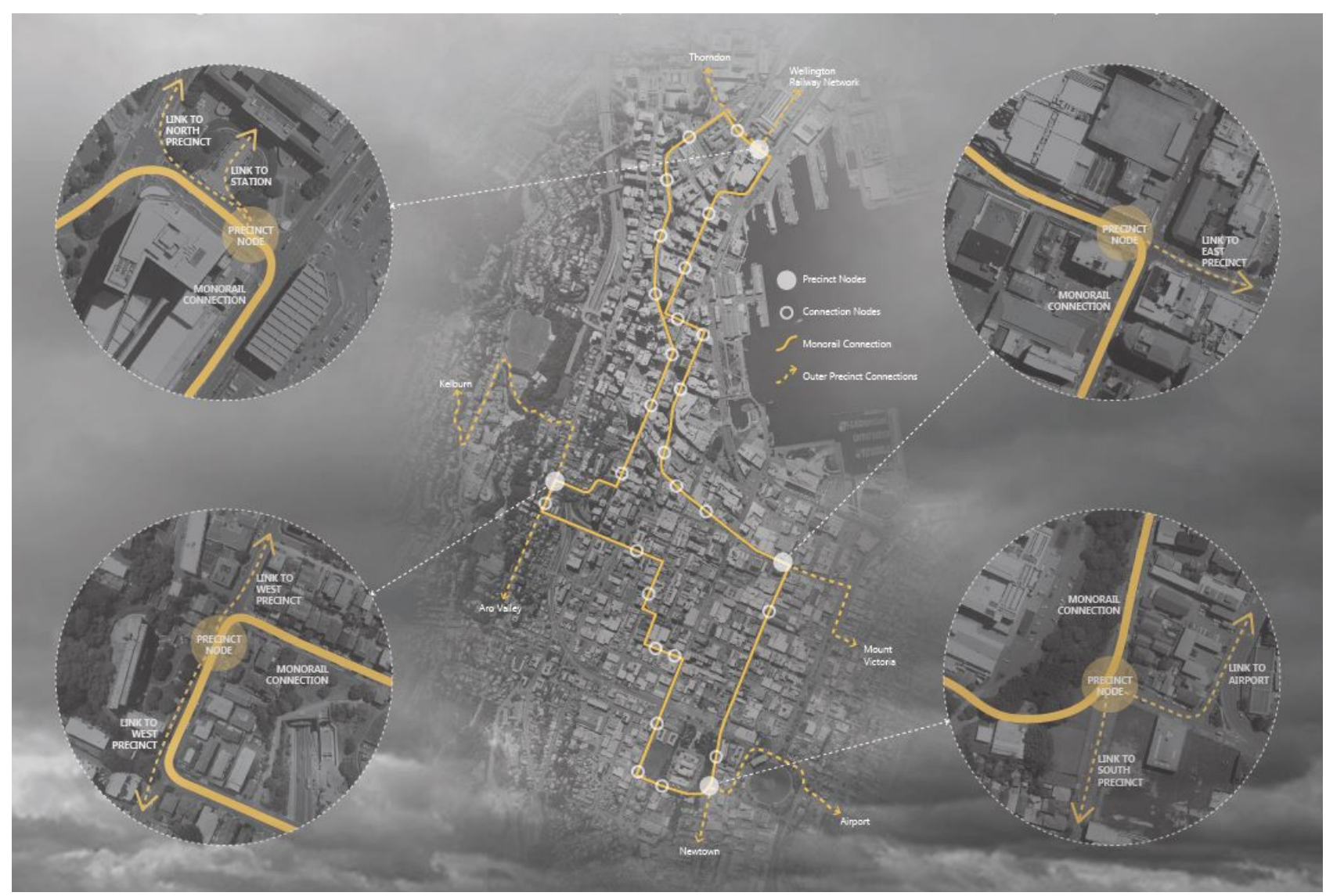

Figure 15. Transport Route and Nodes

Apart from the air space above roads, the building doesn't have a specific site. The development takes place within Wellington City while remaining above ground with a minimal building footprint on the ground to maximise surface area, as it is becoming a luxury. Also occupying the air space is a proposed transport system loop around the city. It defines a path through the city (see figure 15) that is strategically divided into nodes. Each of the nodes shown represents a building. The sites are primarily accommodation structures for students, which is the main focus of this research portfolio, as well as four central hub spaces (see figure 15) that provide amenities that are connected to the city and unified with a cohesive connecting transport system. 


\section{Chapter 3 - Programme Analysis}

\section{I - CLIENT INVESTIGATION}

During the first two months of the research portfolio, it slowly transitioned from a design for homeless people into a design for students in the future, with the proposal that students will find it harder and harder to get accommodation throughout their study. As more information was uncovered about homeless life, the simple idea of designing to help the homeless grew into attempting to help people with many different reasons for living rough, including drug addiction, violence issues, family situations, financial trouble and mental problems (see figure 16). Because of this large range in the potential programme, the project required reconsideration around the client as all clients have different requirements and different ways of life, so a single programme was chosen. After more research and investigation into the future, it was realised that there is an existing problem of students struggling to find a home throughout their studies, which is only going to get worse.

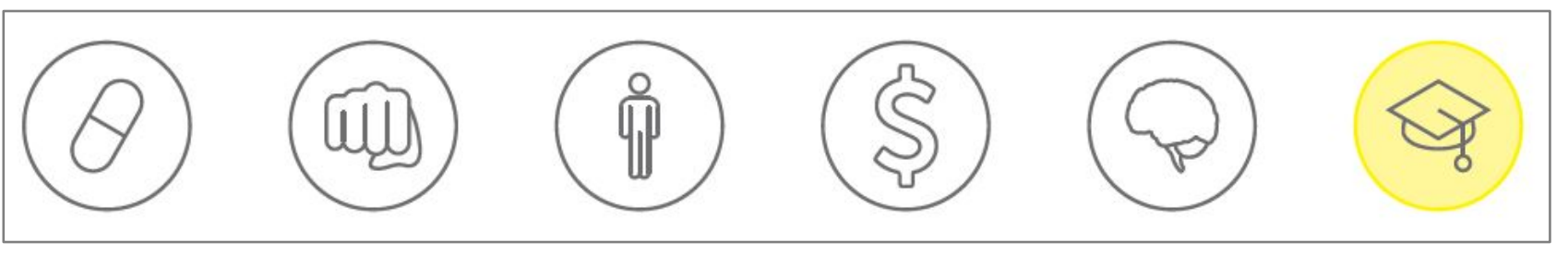

Figure 16. Homelessness Diagram

The perceived new form of homelessness became the focus for this research portfolio, as it is estimated to worsen due to increasing education costs, increasing living costs, Wellington's rising population, and Wellington's exponential growth and looming lack of space. The channelling of the programme to designing student accommodation was very successful for this project as it sparked a new passion, as the topic is much more relatable to somebody who is also going through university.

There were a large range of factors that required testing to align this programme to an in-depth research portfolio but proved a much stronger starting point than the continuation of the fourth year architecture project as it was instantly ore relatable. Some factors to explore were:

- The requirements of the client

- Future estimation to determine the quantity of

- Student hall and student accommodation analysis

- City infrastructure analysis to determine the potential scale of the project

\section{II - PROGRAMMATIC REQUIREMENTS}

A small study, in the form of a survey, exploring student life was done to understand what is needed for a comfortable living situation throughout tertiary education. It involved a simple question, "What do you 
require and look for in student accommodation?" the list that accumulated includes the basics such as waste disposal, power, running water, laundry facilities, adequate lighting, ample storage, and cleaning facilities. Other elements that require an occupiable space include a dining area, kitchen, bed, workspace, bathroom (shower and toilet) and social space. This small experiment was very valuable in that it provided a strong starting point for the planning process of the project, bringing it into reality and highlighting multiple considerations and implications to work through, such as the importance of small space planning to maximise occupancy while still creating a comfortable space. Following this small experiment, further investigation was done into what people want in their own space. A range of preferences were revealed, particularly over different ages and year groups. Typically students in their first years of study are more social and get more out of interaction and communal spaces than somebody later in their education. Students further into their education tend to require more private spaces for study and separate communal spaces for events and socialising. In addition, client/occupant analysis comparisons between flats and halls were implemented to develop an understanding of how the division of spaces could occur, in regards to communal spaces, bedrooms, etc. These experiments led to a solution that uses a system of shared amenities and services with private eating, sleeping, cooking, and living spaces as well as a series of different communal spaces with altering programmes throughout the rest of the design. A large driver for this project is the notion of saving space and minimising scale while maximising capacity, to maintain a low construction and running cost of the final design. The spaces that are private, within the accommodation unit (see figure 17), are individual to the room, which helps to make the space small and compact, with the lack of people that would be able to occupy the space (one person or a couple who can live in close proximity to each other). Keeping it to a single person (or a couple) has many benefits, including maximising productivity and minimising potential damage from a lot of people in a small space, as well as keeping each room small in scale, to ultimately reduce the overall size of the design.

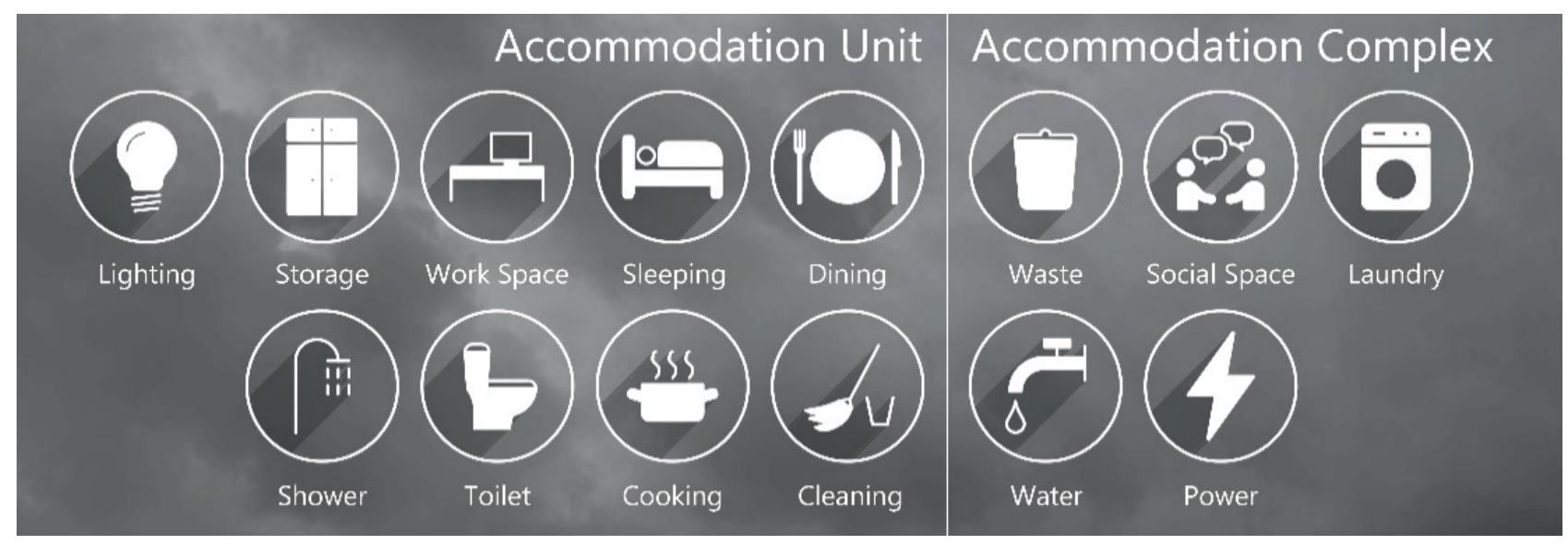

Figure 17. Client Requirements 


\section{III - PROGRAMME SEPARATION}

The building programme was divided into four more manageable components to allow a detailed final design outcome at each stage of the project (see figure 18). This was a very successful method of designing for a large scope as it produced a strong design and programme for each component, however, the first step set the direction for the entire project, which could have been done differently. It started the project in a specific direction and caused subsequent components to follow the same style and method, which worked well, however it highlighted a series of issues. The main issue was that it became difficult to maintain a sense of coherency and unity throughout the project. If this project were to be continued in the future the design process would have been repeated a second time, only this time as a single design instead of four individual ones, to link the components together. The breakdown of design components helped to achieve the separate aims and objectives as they relate to different parts of the project, for example, the transport section looks at solving Wellington's density by removing the need for car parks, therefore opening up more space for the city to grow.

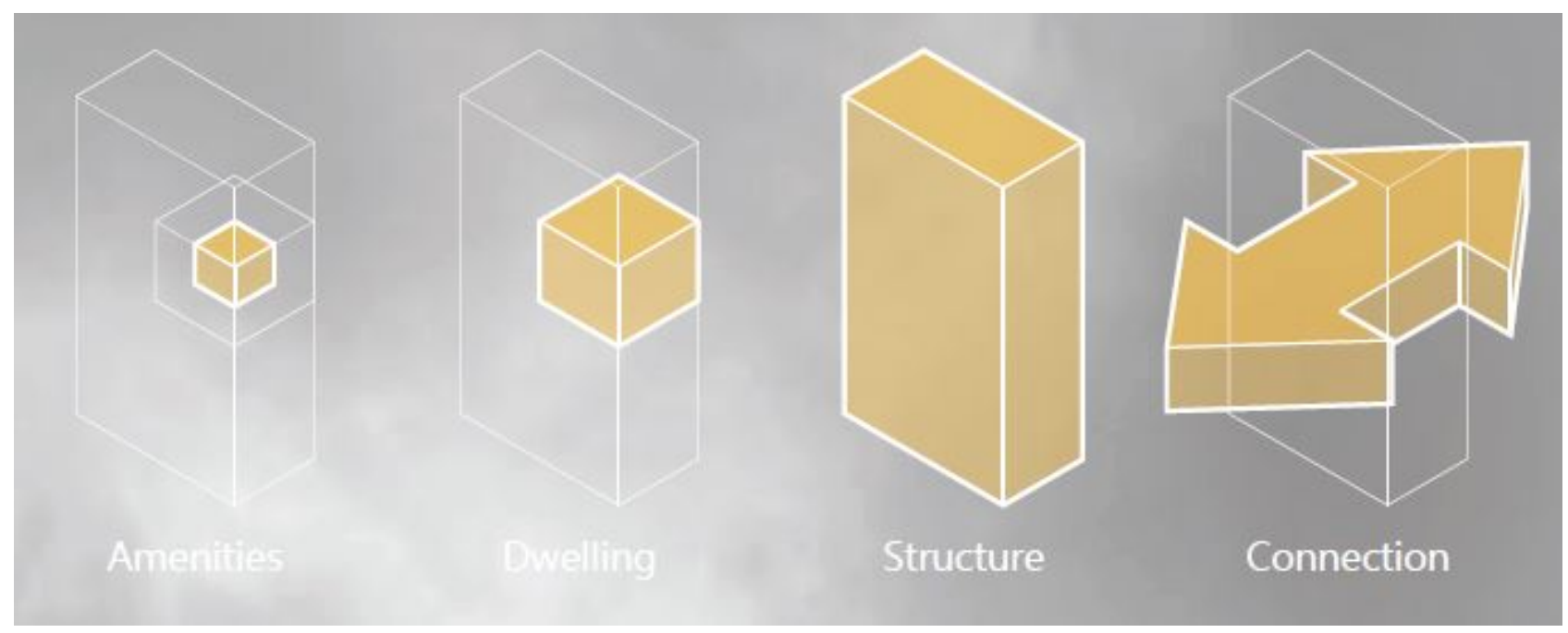

Figure 18. Design Components

\section{IV - PROGRAMME EXPERIMENTATION}

Experimentation was done into the most suited planning arrangement for the student dwelling. Two main unit types were explored, expanded on, and compared to arrive at design solution dwelling. The figure below (see figure 19) shows an exploration of a singular module hosing all amenities and a unit with multiple modules, each housing a different amenity. This process was very useful in that it was then expanded on and investigated more thoroughly, expanding the range of possibilities for how the accommodation might take place. Each unit design utilises a different system that provides each with a certain uniqueness, each with their own implications and success. After a comparison of each unit (see figure 20) a few interesting things were discovered. Firstly, the most suitable module design was found to be the singular module over the multiple 
modules, as it requires less infrastructure in the form of unit connections, fewer internal partitions, and smaller overall size. The single units also provide more internal customisation. With the multiple units, each space is defined by an enclosure, while in the single module there is much more freedom for different planning arrangements and exciting interactions between spaces.

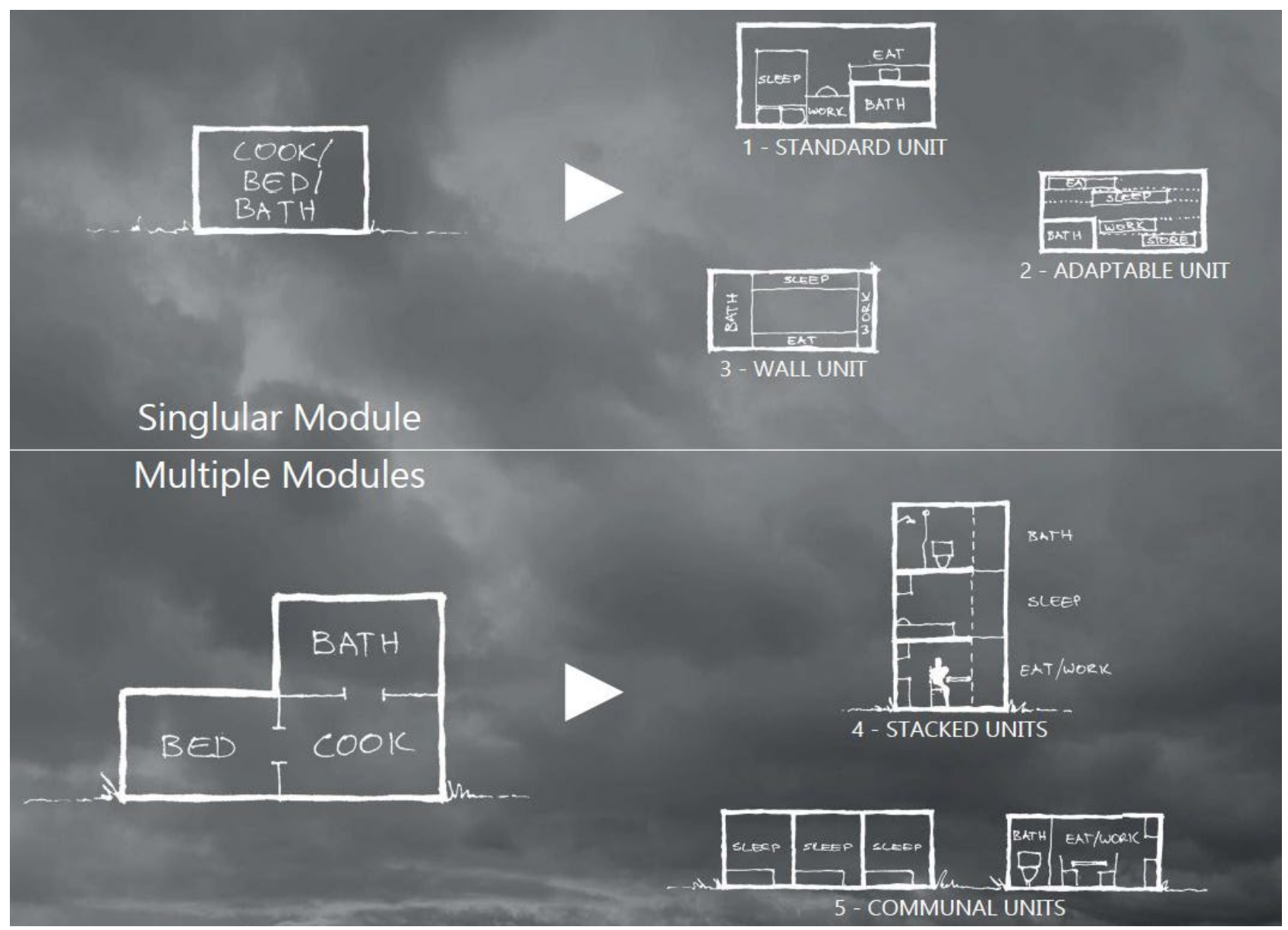

Figure 19. Amenity Module Study 


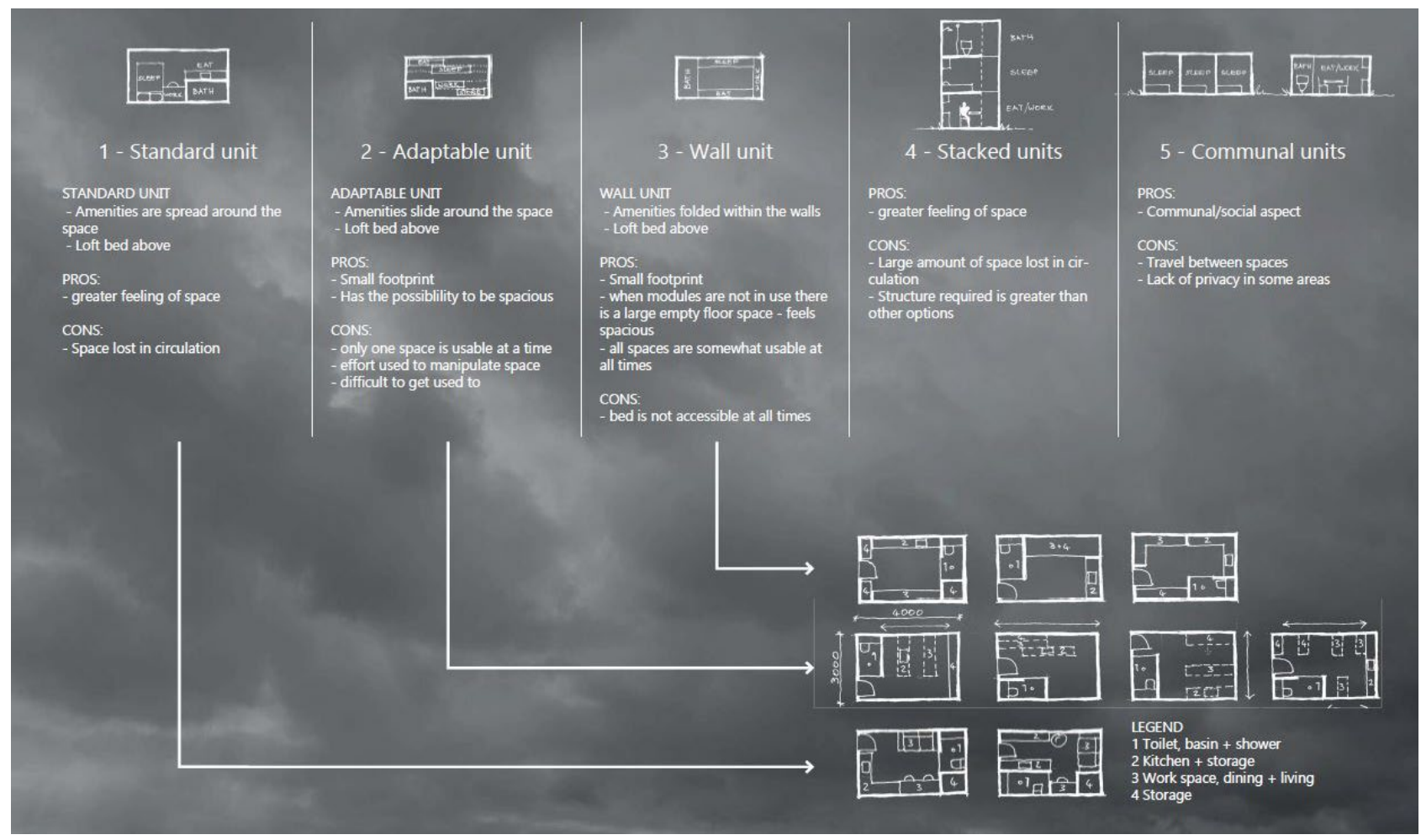

Figure 20. Amenity Module Comparison

This experimentation and comparison process was very valuable to the project as it defined exactly the direction that the project was to continue in. it did this by highlighting the positives and the possibilities and the implications with each design decision and revealed that a single standard unit with aspects of all explored design options would be best suited.

\section{V - PROJECT SCALE}

The student capacity of the overall design was left open, however, each design consisted of a minimum of 24 rooms and a maximum of 56 rooms, therefore a minimum capacity of 24 people (all individual) and a maximum capacity of 112 people (all couples). This number would be multiplied by the number of structures constructed which could be increased or decreased (based on the project) in accordance with the number of required accommodation units. This gave the project flexibility to allow a phase aspect to be considered. Early on, only a few structures would be built and when necessary, more would be added to the transport route to account for the cities growth. 


\section{Chapter 4 - Literature Review}

A series of key ideas, authors and theorists were a large influence throughout the process of this research portfolio.

\section{I - RENE DESCARTES RATIONAL METHOD}

Rene Descartes' methodology rationale was utilised to provide the best opportunity for project success. Descartes' rational method consists of breaking up the project into a series of small investigations and expanding from that. He outlined the method in four main rules:

"QUOTE UNAVAILABLE" (Descartes, 1637)

Descartes' method was used throughout the project by breaking the process down into smaller components to create smaller more manageable design experiments. This proved very useful but highlighted some issues, namely that each component becomes individual and it became difficult to maintain a strong relationship between different components in the later stages of the project.

\section{II - CYNICISM AND THE LIFE OF STUDENTS IN ANCIENT GREECE}

In 'Wandering in Ancient Greek Culture', Silvia Montiglio (2005) discusses Cynicism and the wisdom and freedom of homeless wanderers. Cynicism is a philosophy from ancient Greece that states that life should be spent with nature, not desires such as wealth, power, health, status or possessions. Cynicism was first explored by Socrates' pupil, Antisthenes and then expanded on by his pupil Diogenes. Diogenes preached to the public about his chosen lifestyle of poverty, the rejection of desires and welcoming of freedom (Montiglio, 2005). The concept for Upliving uses these principles of 'wandering the streets' by connecting too many areas throughout the city, becoming permeable by weaving into the urban fabric. 


\section{III - METABOLIST ARCHITECTURE}

Metabolist architecture was a large influence for this research portfolio and has a strong connection with the concept design phase of the building structure, exploring a large hanging structure and a large stacked structure, with rigid forms and a simple material palette.

\section{IV - LITERATURE DISCUSSING HOMELESSNESS}

"QUOTE UNAVAILABLE" (Smith, 2013)

In 'In Defence of Homelessness', Andrew F. Smith (2013) suggests that homeless people are considered as outsiders as they are in an in-between stage. He suggests that they do not fit into any particular crowd. The same can be said for students in that they are in between childhood and a potential career. Smith (2013) suggests that homeless people should be provided with housing near areas of congregation. This can be applied to students with the commonly used spaces such as university campuses, cafes, parks, libraries, etc. This is relevant in that it highlights the fact that students require life near their university for comfort and convenience. He also suggests that homeless people find it hard to fit in, and students are the same.

"QUOTE UNAVAILABLE" (Quinn, D. 2000)

An important idea that is discussed in the text Beyond Civilisation by Daniel Quinn (2000) is that homeless people occupy certain spaces, which is not necessarily favoured by all. Instead of trying to remove them from where they are comfortable, spaces should be designed for them around those areas, instead of attempting to move them. This can be applied to students in a similar way to the ideas in In Defence of Homelessness by Andrew F. Smith. 


\section{Chapter 5 - Project Review}

I - KEY PRECEDENT ANALYSIS

\section{Daniel Illum-Davis - Rough | Housing the Homeless in Westminster}

IMAGE UNAVAILABLE

Figure 21. Rough

The thesis project 'Rough' by Daniel Illum-Davis aims to create transitional accommodation, through rehabilitation, for people sleeping on the streets in Westminster. It lets people adjust at their own pace, helping to prevent the shock of sudden change and the resistance often associated with moving off the streets. The building manifests itself as a secure personal space with blurred boundaries between inside and outside that is of a similar environment to what homeless people are used to, making for a smooth transition toward rehabilitation (Illum-Davis. 2012). Rough uses a communal environment that creates comfort and security for occupants.

\section{Milo Ayden De Luca - Excrescent Utopia}

De Luca investigates street lights, on the streets of London, as support for temporary, light, and movable dwellings for homeless people. The dwellings utilise a tensile sailing boat aesthetic achieved with the use of guy ropes and pulleys to tie down the structure, mixed with inexpensive, basic, and recycled materials. The dwellings incorporate horizontal boxes for sleeping, and vertical boxes for activities such as busking (Chalcraft, E. 2013). Excrescent Utopia shows an effective way of maintaining a minimal footprint and can be applied to a larger scale. 


\title{
Stéphane Malka - P9 ghetto-mobile as a nomadic micro-city
}

\author{
IMAGE UNAVAILABLE
}

Figure 24. P9

The 'P9' project utilises a modular system mounted on scaffolding, with footbridges and public spaces that can be easily adapted to suit different urban requirements. The scheme is run by the residents and is organised around several modular programs including dwellings, offices, art galleries, recording studios and night clubs (Malka, S. 2014). It effectively uses a modular design to create a flexible program for each space to suit different requirements.

\section{Kisho Kurokawa - Nakagin Capsule Tower}

IMAGE UNAVAILABLE

Figure 25. Nakagin Capsule Tower

The previous precedents led to a look into Metabolist architecture, specifically the Nakagin Capsule Tower (see figure 25). The tower has a uniform structure and array of dwellings, using a small footprint with maximum dwellings and minimal circulation (only a central core that feeds directly into the dwellings). 
The Halfway Neighbourhood - Josh Roberts, fourth-year architecture project

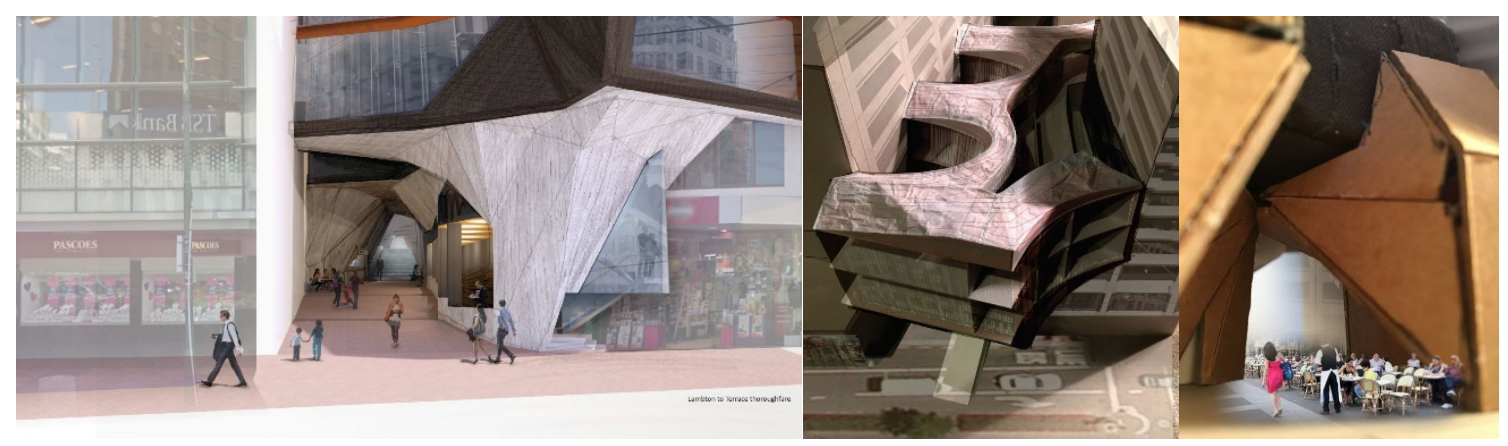

Figure 26. The Halfway Neighbourhood

The Halfway Neighbourhood aims to rejuvenate an otherwise derelict pedestrian access (Farmers Lane, between Lambton Quay and The Terrace) and provides accommodation for homeless people. The accommodation helps to transition homeless people from the streets back into society by providing guidance, communal living, job support, knowledge and therefore opportunities to make money and stay off the streets. The final design utilises a progression system for homeless people to encourage hard work and personal development with the reward of an increase in the quality of accommodation as you progress through the building. A vibrant thoroughfare at ground level between Lambton Quay and The Terrace entices people and leads them into the building. The building unites people and makes the accommodation a communal and beneficial place for homeless people to reside in. A large part of this section was the critical review of the fourth year project with a theme similar to this one, except it was a futuristic take on providing accommodation for students, rather than homeless people. The project transitioned to providing accommodation for students following the critical analysis of the fourth-year project, which identified that homelessness was much too broad and would require refinement to programme. This challenge was furthered by the difficulty in relating to the situation that homeless people would be in, which instigated the move to the programme of students, which was much more relatable. The new client gave a much more grounded perspective and a more clear direction to continue the project in. The chosen path for the research portfolio was changed approximately two months into the project, which caused a lot of early research to be less relevant as it looked deeply into the life of homelessness. This prior research was interesting so was made relevant with the proposal of students becoming homeless in the not so distant future. 


\section{Broadacre City - Frank Lloyd Wright}

IMAGE UNAVAILABLE

Figure 27. Broadacre City

Frank Lloyd Wright's utopian project Broadacre City was a plan for a vast community that Wright worked on from the 1930s until his death in 1959. This is a great example of visionary architecture that was useful in this research portfolio because it paved the way for futuristic thinking. Wrights design for Broadacre City proposes that everyone will have an acre of land to fulfil the American dream. As we can see this has become unrealistic due to population growth and sustainability implications, however, provides an excellent example of the far-fetched nature that can be achieved with some passion and brilliant ideas. This Research portfolio aims to achieve a similar sense of future thinking, however instead of wrights attempt at fulfilling everyone's 'American dream,' it explores the question - What would happen if Wellington city's students became homeless?

\section{A Plan for Tokyo - Kenzo Tange}

IMAGE UNAVAILABLE

Figure 28. A Plan for Tokyo

Kenzo Tange's 1960 utopian project 'A Plan for Tokyo' has a similar theme to wrights, only instead of trying to fit everyone's dream into a single area, Tange is trying to fit everyone into a single area. Wright accommodates the growth in people's dreams with a rather futuristic approach while he accommodates growth in population. Wright was optimistic in his endeavours with Broadacre city when it came to providing everyone 
with a large amount of space, whereas around the same time, Tange takes a more realistic approach that attempts to create space upon a bay to accommodate the growth in population. Wright's and Tange's designs are two very different approaches but both have great value in highlighting the necessity to speculate.

The precedent investigation was very valuable because each precedent highlighted relevant design approaches and ideas that were used throughout the design process of this research portfolio, which provided a strong basis for many programmatic and design decisions that have been made.

\section{II - PRECEDENT DESIGN COMPARISON}

To expand on the ideas and methods investigated in the Key Precedent section above, an assortment of relevant precedents that were influential in their design was collated and then compared (see figures 29, 30 , 31, and 32). This process helped to form a direction for the design style and provided a starting point for different elements. Completing both the key idea investigation and the key design investigation alongside each other was a very worthwhile exercise, as it provided simultaneous development of both a theme and a design style. The Key Ideas investigation provided a strong direction for the project, developing the idea into student accommodation with futuristic and large scale attributes. The precedent comparison was valuable as it highlighted effective methods of understanding such ideas. It provided the 'how' while the key ideas were the 'what' and 'why'.

IMAGE UNAVAILABLE 
Upliving - Student Accommodation

IMAGE UNAVAILABLE

Figure 30. Precedent Matrix 2

IMAGE UNAVAILABLE

Figure 31. Precedent Matrix 3

Joshua Roberts 
Upliving - Student Accommodation

IMAGE UNAVAILABLE

Figure 32. Precedent Comparison 


\section{Chapter 6 - Preliminary Design}

As part of 'The Halfway Neighbourhood' project that was completed in fourth-year, a series of principles were defined that became a large part of the beginning of this project, although changing throughout the process of the project it provided a strong basis to branch this research portfolio from. The principles included the accommodation of people who couldn't otherwise find a place to live, the provision of a space to grow both socially and through knowledge and skill, the requirement of a space that didn't cost the city negatively in terms of sustainability and building footprint, and the use of poorly utilised spaces. The fourth-year project developed a strong passion that projected into this project with a slightly different research question that has formed a different solution, however, strives to achieve similar goals.

\section{I - INSPIRATION}

The project began without much direction, so the first logical step was to investigate a series of precedents to explore the possibilities of housing for people out of homes. The first project review exhibits a range of living styles however successfully aligned the research question with a direction. The initial direction of the project stemmed from 3 main precedents, which highlighted the potential for designing student accommodation (see figures 33, 34 and 35 below).

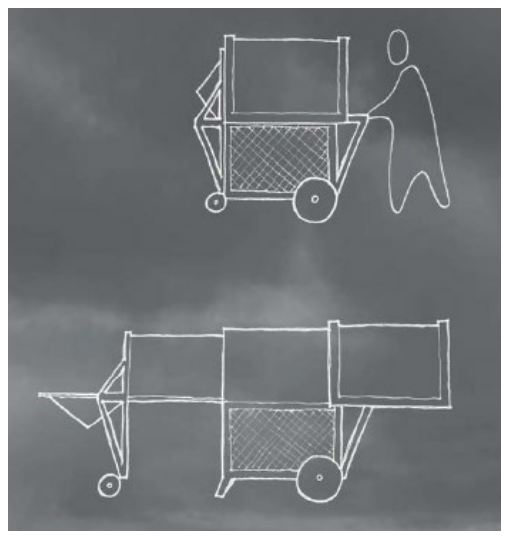

Figure 33. New York Trolley

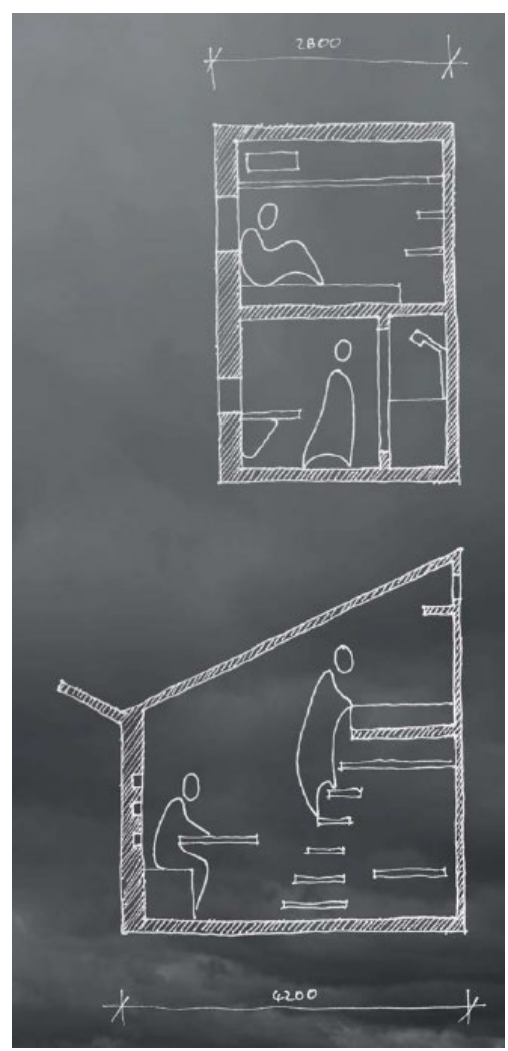

Figure 34. Student Flat

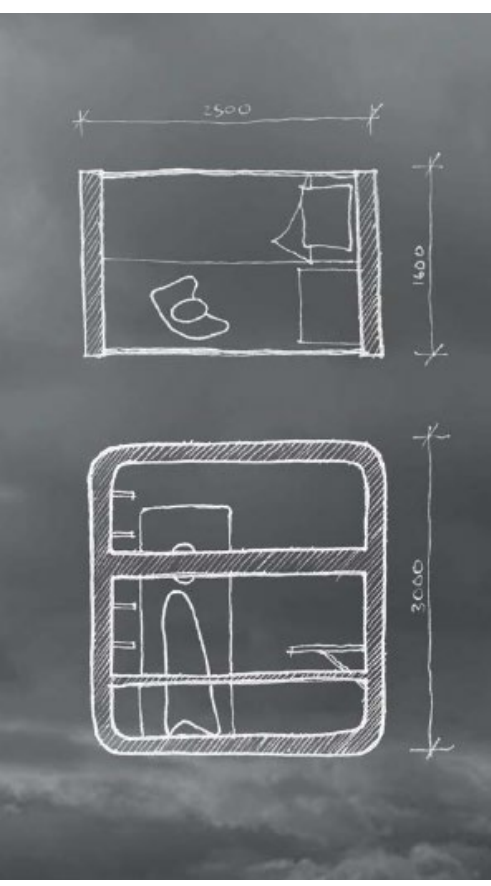

Figure 35. Sleepbox 
The first precedent is a homeless trolley designed by Krzysztof Wodiczko (see figure 33) that has similar traits to a tent in that it can be transported and then folded out and utilised as a place of refuge. The second is a student flat by Tengbom Architects, constructed mainly from plywood with a strong focus of mass production and the minimisation of space. The third is called Sleepbox designed by Arch Group that primarily provides overnight accommodation within airports. All of these precedents were huge influences for Upliving, which can be seen in the final design. The first precedent exhibits a portable aspect that is seen in the design of the moveable amenity space within the dwelling. The student flat precedent is evident in the final designs strive for a minimal building footprint. The Sleepbox's influence is visible in the temporality of the final projects aim for rapid construction, minimal aesthetic, and concise programme. The initial inspiration precedent exercise proved very valuable as it was a great way to start the project with three different ideas that could be combined (because of similar aspects) and reiterated throughout the project as a sort of set of principles to refer back to, to maintain a clear method.

\section{II - ABSTRACT EXPERIMENTATION}

Following a look into precedents, an experiment was implemented to produce an interpretation of the designs with consideration to the client/occupant. This process led to a series of collages that explored parasite dwellings, moving/moveable dwellings, and also structures and dwellings that were separate from the earth to minimise the footprint (see figure 36 below). This is a very imaginary interpretation of the precedent designs but provided another vessel in moving closer to a final design solution. The floating city questions the student flat, the crawling city questions the New York trolley and the structure mounted between buildings represents the Sleepbox. This exercise was very constructive to the research by design process as it brought the project away from existing, premade examples into new ideas that could be developed from, even if they are outlandish and farfetched.

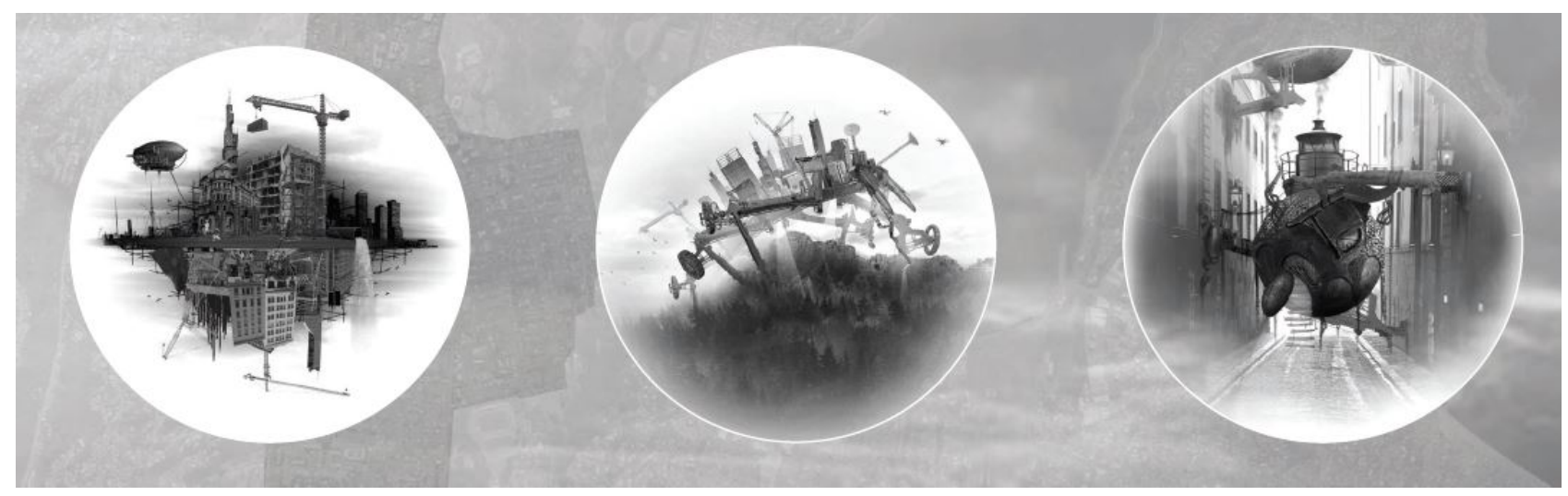

Figure 36. Preliminary Design Collages 


\section{III - CONTROLLED EXPERIMENTATION}

The collage experiment sparked a new inspiration and enthusiasm for parasitic dwellings, which had a strong place in a dense wellington city, particularly with the goal of using underutilised spaces. Following this collage experiment, a further sketch experiment exploring site and context was produced, consisting of a series of sketches overlaid on photographs of existing buildings (discussed in the site experimentation section in Chapter 2 - see figure 13) within wellington as a way to ground the project, giving it a sense of tangibility to expand from. This process was crucial because it gave the project a sense of realism to start basing the method, processes and design experiments from. This process gave the project a sense of direction and potential for development.

Further controlled experimentation was completed in the form of model making. This experiment looked at a series of specific underutilised site typologies and aimed to fill them with a rather random form that could be occupied by a student (see figure 37). This experiment furthered the design idea, opening up possibilities with materiality and form, initiating a strong development of the design process.

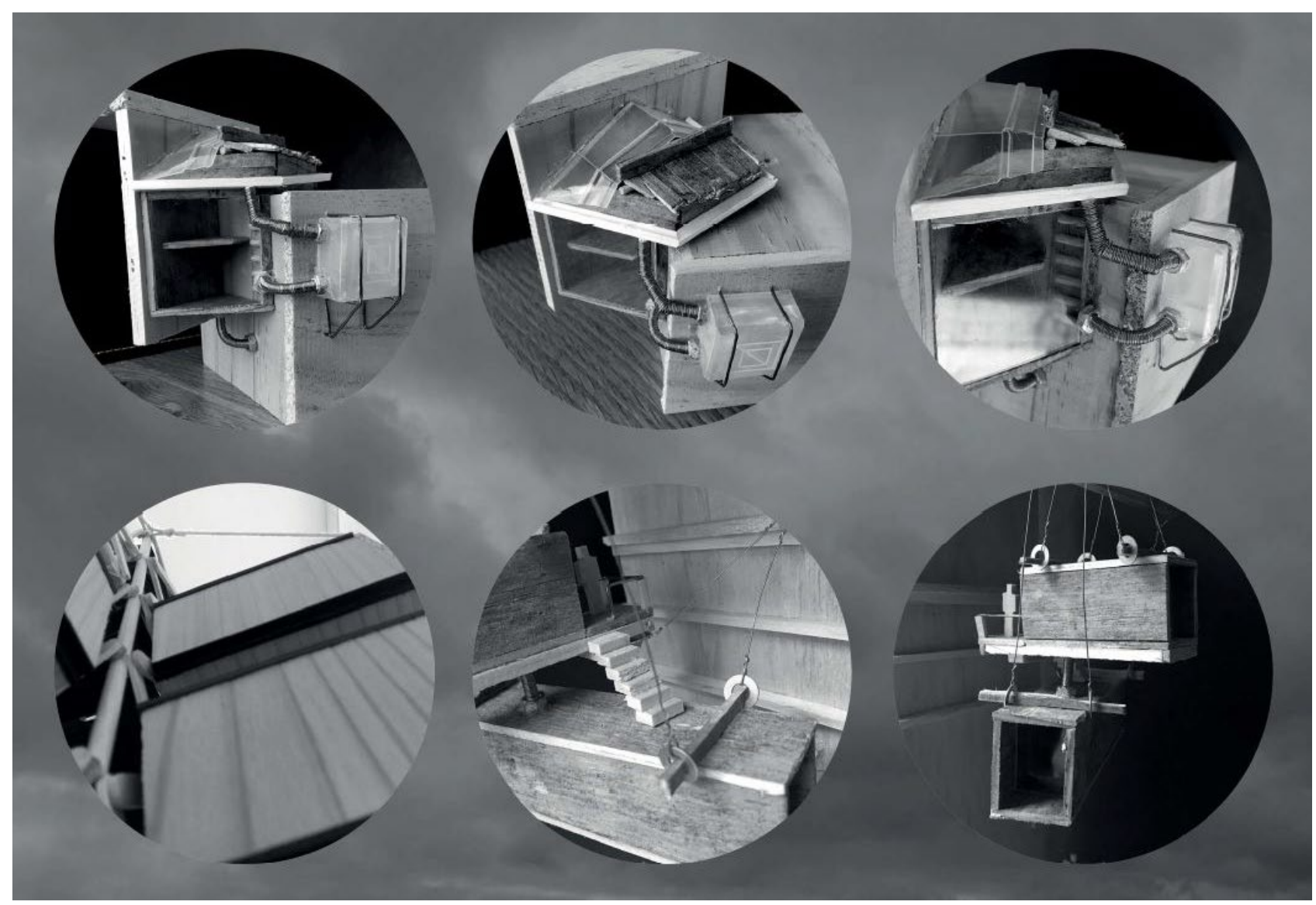

Figure 37. Dwelling Model Concepts 


\section{Chapter 7 - Developing the Design}

\section{I - DESIGN PROCESS}

This process is a bit different than some standard design processes, it was good to try a different method to explore different possibilities and find new ways of designing. This section combines both concept and developed design for this research portfolio. The project, following preliminary design, took on a process of development through iterative design, continuing from preliminary design into detailed design. To begin development of the project, Rene Descartes' rational method was implemented, particularly his second rule, "to divide each of the difficulties under examination into as many parts as possible, and as might be necessary for its adequate solution" (Descartes, 1637). The project scope was divided into 4 smaller components (see figure 38), each with a different role in the design and a different scope. Each component was individually tested through the use of iterative model making and sketch experiments, then critically evaluated. This process allowed each component to have a very strong design rationale and justification, however, it caused each component to be rather separate, and lack a strong link to each other. To further this element of the project a critical evaluation of all aspects combined would have been useful and then a separate development stage (as stated in the methodology) to bring the elements together and form a strong unified design.

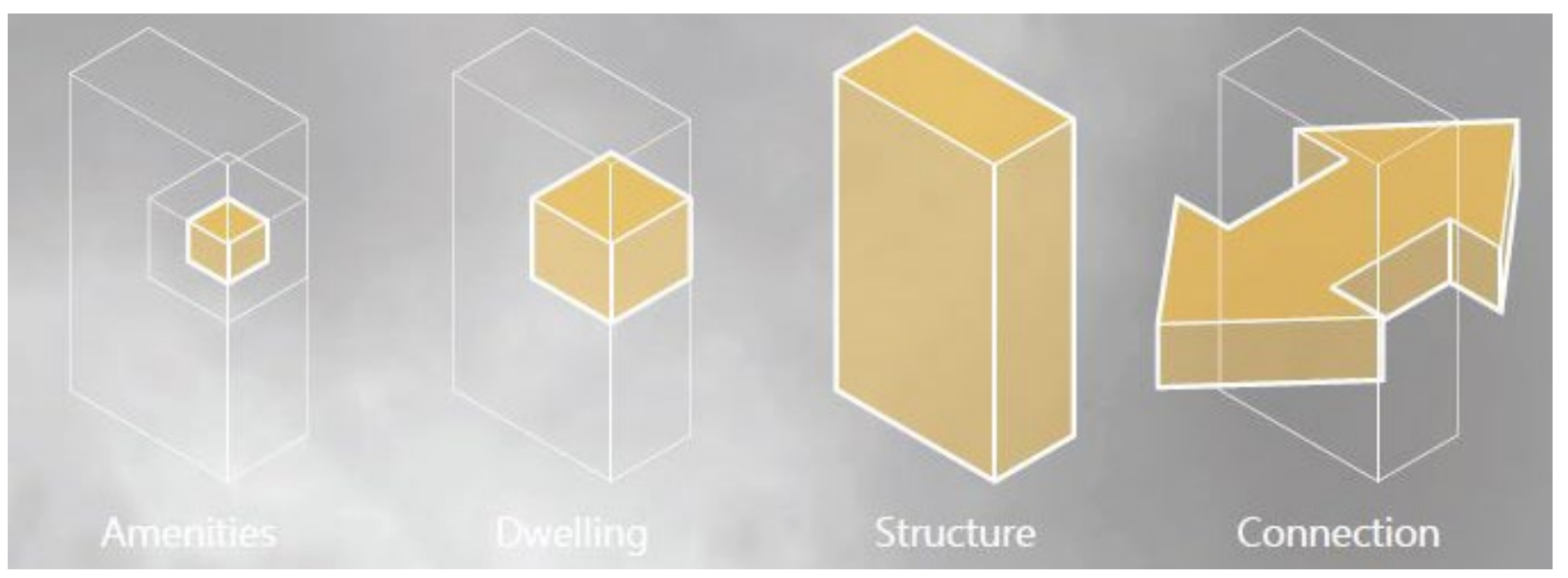

Figure 38. Design Components

The early stages of this design phase highlighted some issues with the initial site investigation that looked into multiple typologies. It revealed the need for a single typology that the project could attempt to resolve, giving the project more purpose and direction. The typology that was elaborated on, is the air space above Wellington city's road system (as discussed in Chapter 4, III - Site Selection). A single uniform site provides a coherency to the project and outlines a standard, and a set of parameters, which was very valuable in a project that has so many. By focusing on many different typologies, the project would have diverted and turned into many smaller projects, each with a different design, which attempted to solve different site problems.

\section{II - DESIGN EXPERIMENTATION}


Following a similar methodology that has been developed throughout the other design stages, the project development was continued in the form of sketch and model making experiments. Each of the four components was developed thoroughly from preliminary design experiments into a final developed design (see figures 39, 40, 41, and 42 below).

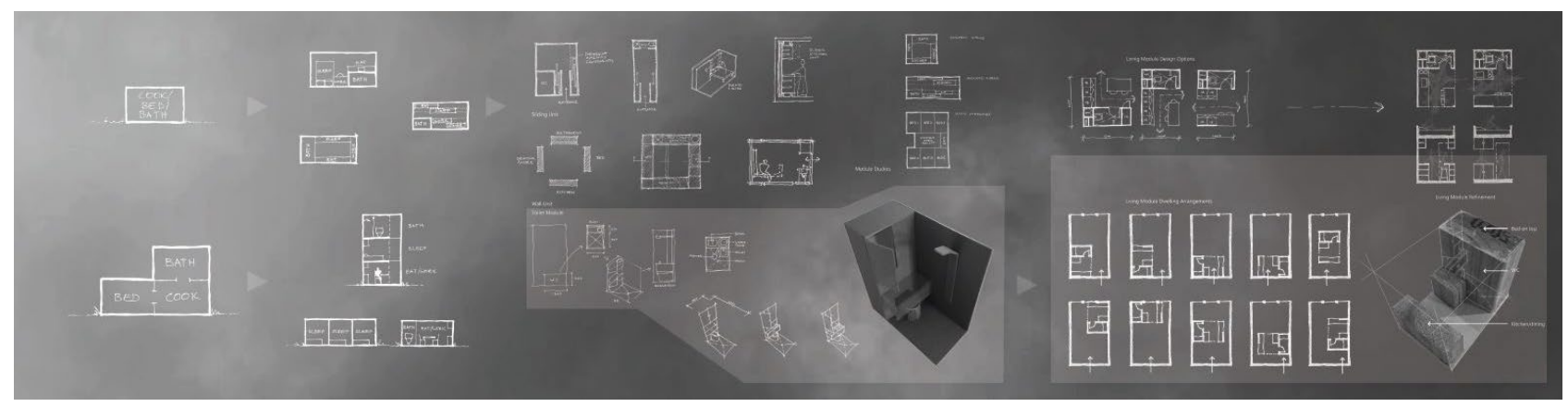

Figure 39. Amenity Development Process

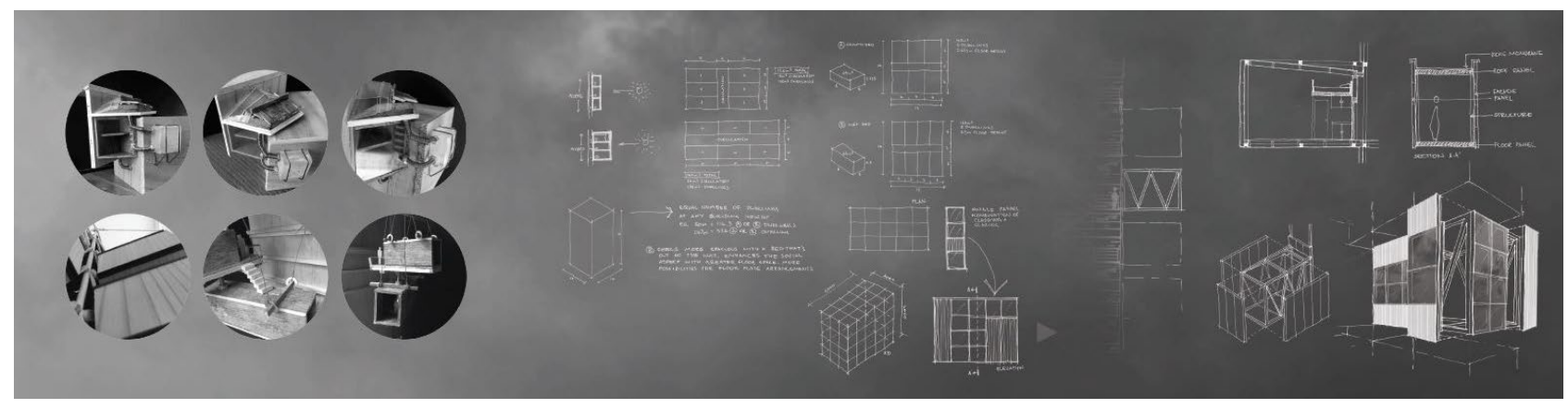

Figure 40. Dwelling Concept Process

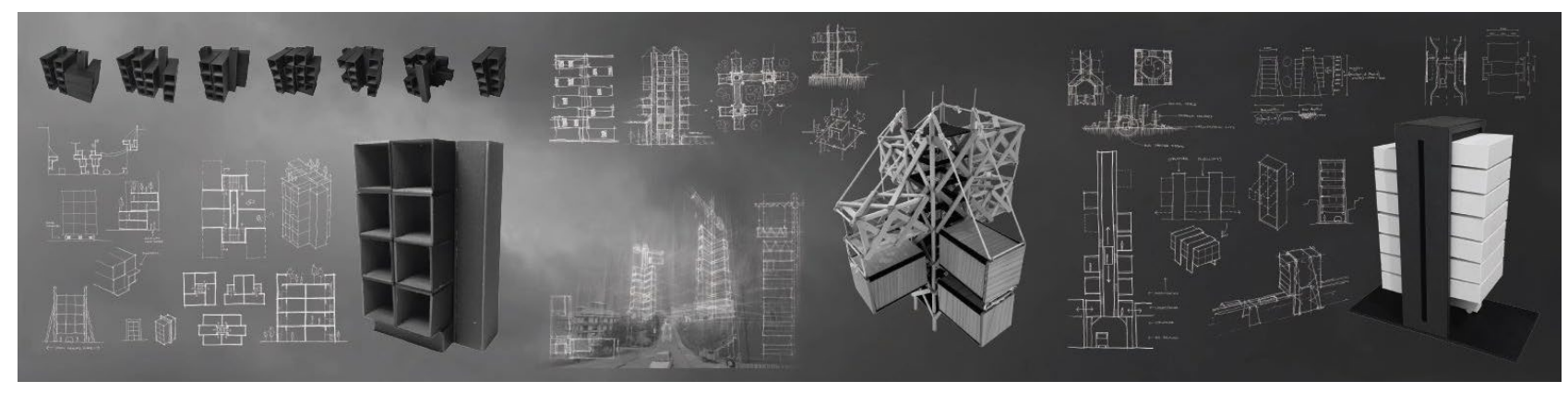

Figure 41. Structure Development Process

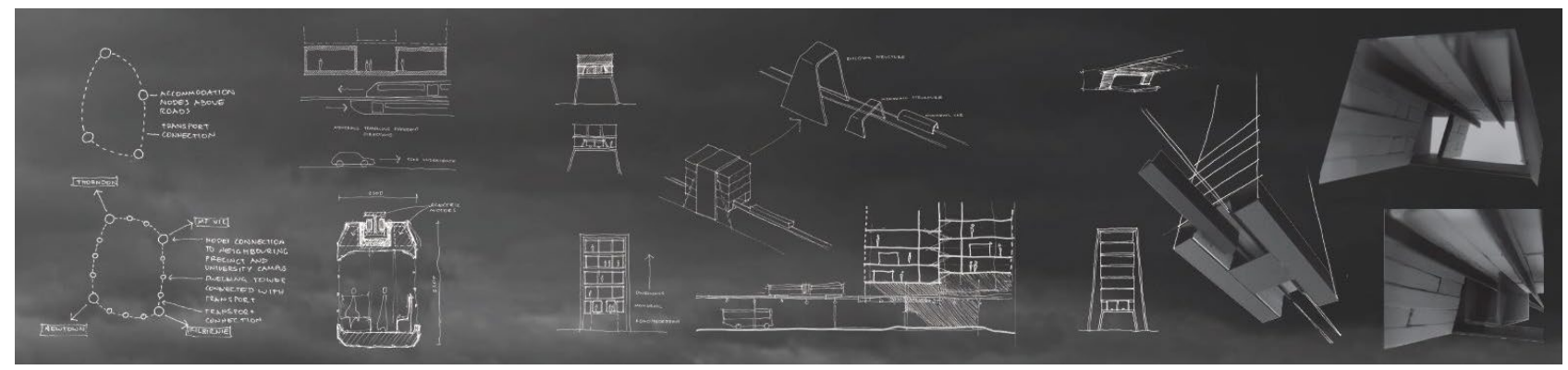

Figure 42. Connection Development Process

This iterative model making and sketch design process was very methodical, helping each stage to arrive at a resolved solution. It is an effective method of beginning from an idea and ending with a design. 
Some design experiments were a small part of the whole design process, each with slightly different approaches, however, were very important as they helped to find new information and discover different aspects that might not come through in other methods (see figures $43,44,45$, and 46 ). Changing up the design approach through materiality and scale proved an effective method of producing many different aspects of the design. Each design led to something else which with the change in the materiality of the models provided a sense of irregularity and surprise to each step of the development. The surprise element made the process very exciting as each step sparked new inspiration and new design ideas, morphing and strengthening the project while it was designed.

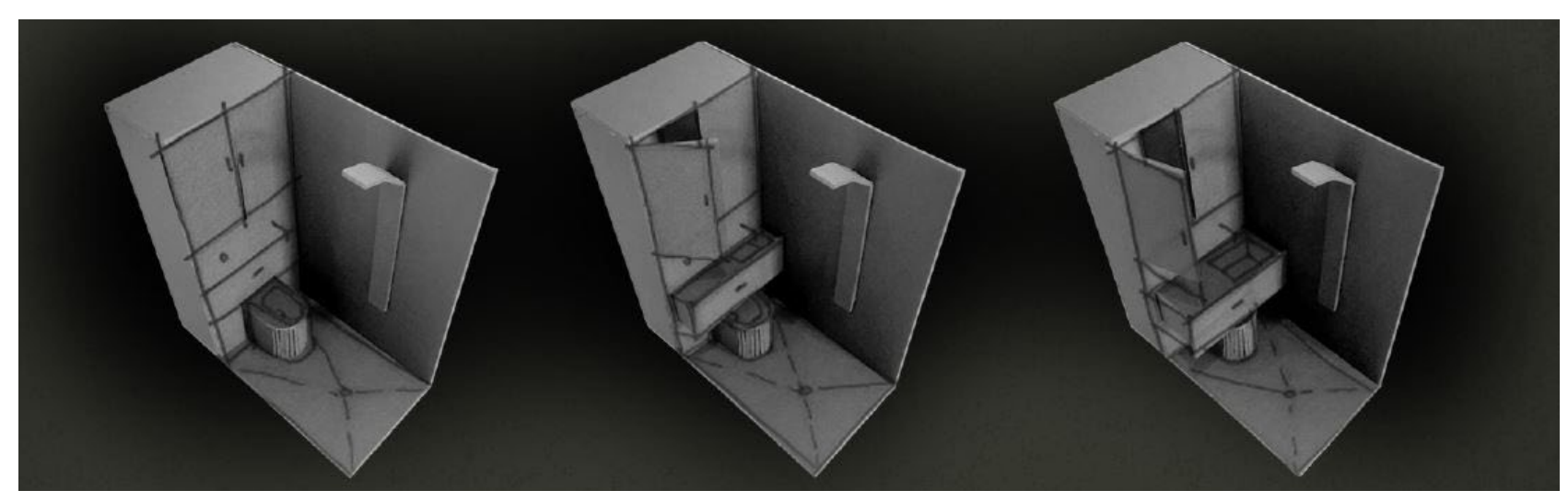

Figure 43. WC Design

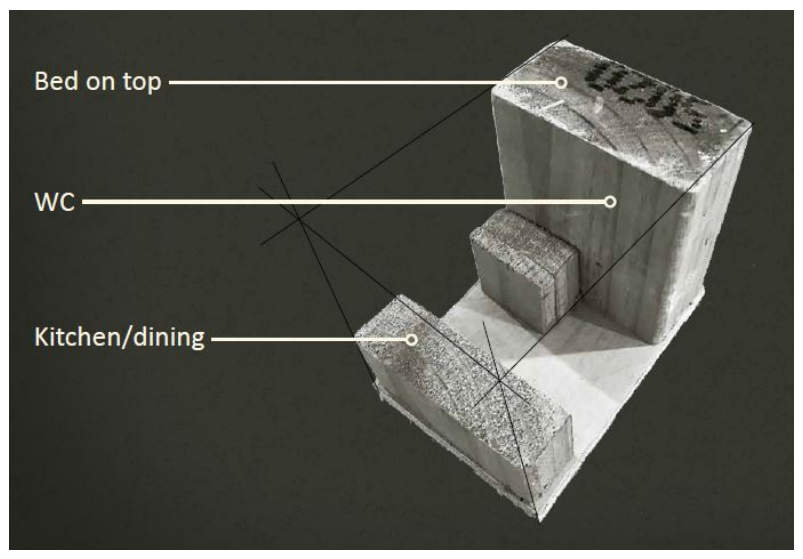

Figure 44. Amenity Module Design 


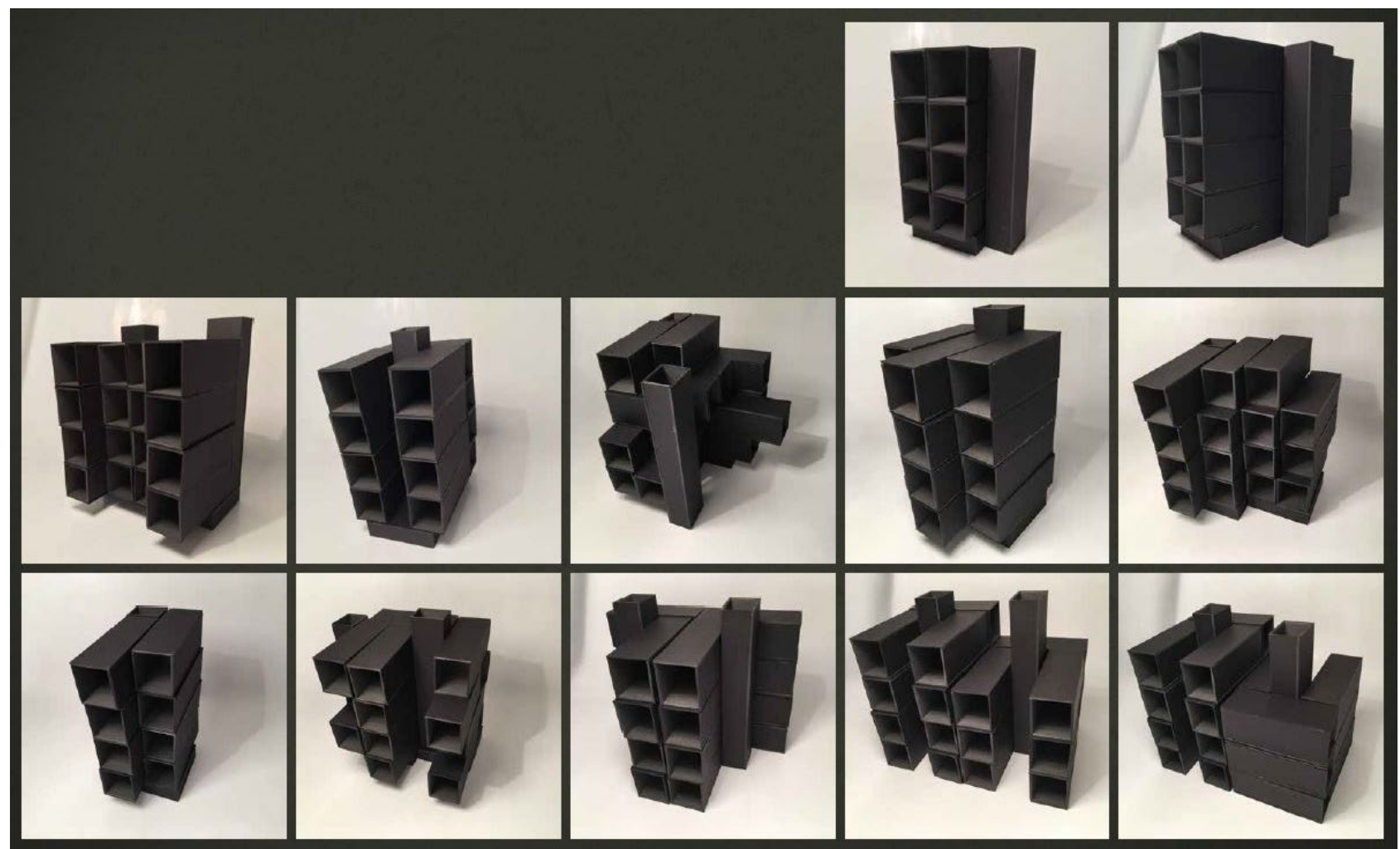

Figure 45. Structure Model Concepts 1

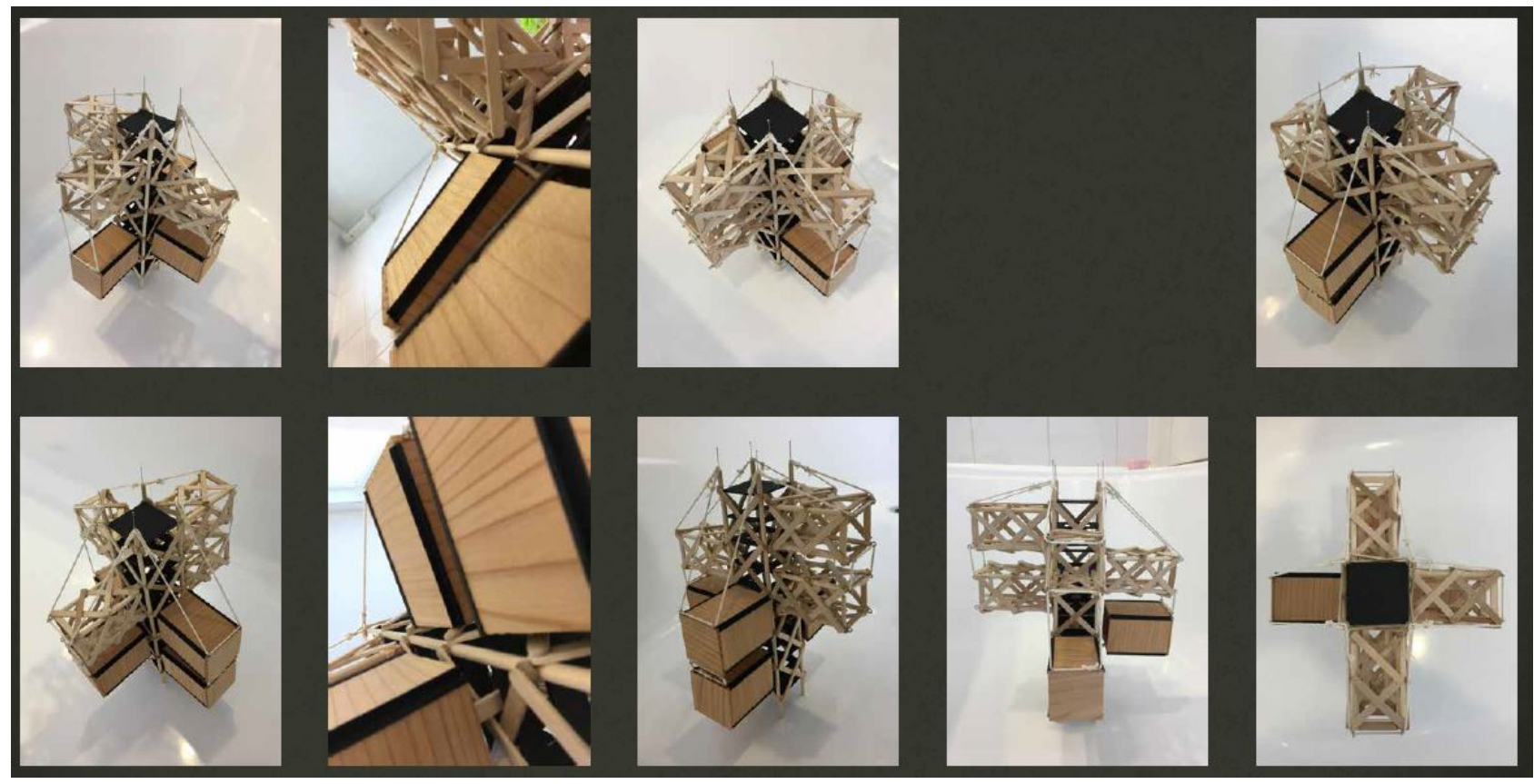

Figure 46. Structure Model Concepts 2

This process was a very powerful tool to experiment rapidly and produce many ideas that could instantly be written off or designed further. It was a great way to push the design to the next level

A strength of the project was the extensive research into the target market, which led through many design stages but subsequently caused them to become less of a focus for the project. Research and design experiments were larger in the context and programme analysis sections to fully decide on and describe the target client of the project. The project was small due to a limited timeline and limited resources, which meant 
certain aspects had to be partly sacrificed to achieve a resolved design. Majority of the focus was put into the early experimental stages of the project and then subsequently the end stages. This left a gap in the developed design section as highlighted in the methodology.

\section{III - DETAILING THE DESIGN}

The process of the detailed design solution included taking the final developed design models and ideas and with consideration to all of the previous chapters (particularly the project review, literature review, programme analysis, context analysis and developed design), transforming them, with knowledge of construction, into a final design solution. This section utilised less experimentation and critical reflection than other stages as the majority of the project was in the earlier stages. The methods utilised in the detailed design stage of the project consisted of 3D digital modelling that took the small scale physical models that ended the developed design stage, into a more realistic environment with a larger scale, that provided a way to resolve many smaller elements that would not be possible with the clumsy nature of sketch and modelling experiments (see figures $47,48,49,50,51,52,53,54,55$, and 56 ).

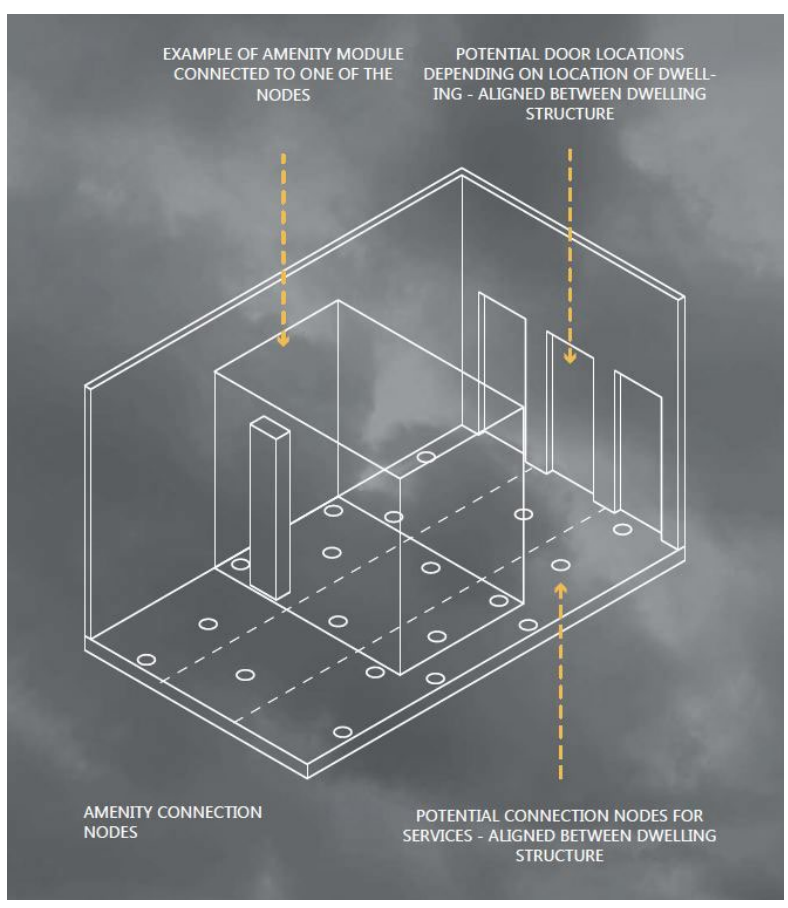

Figure 47. Amenity Customisation Diagram

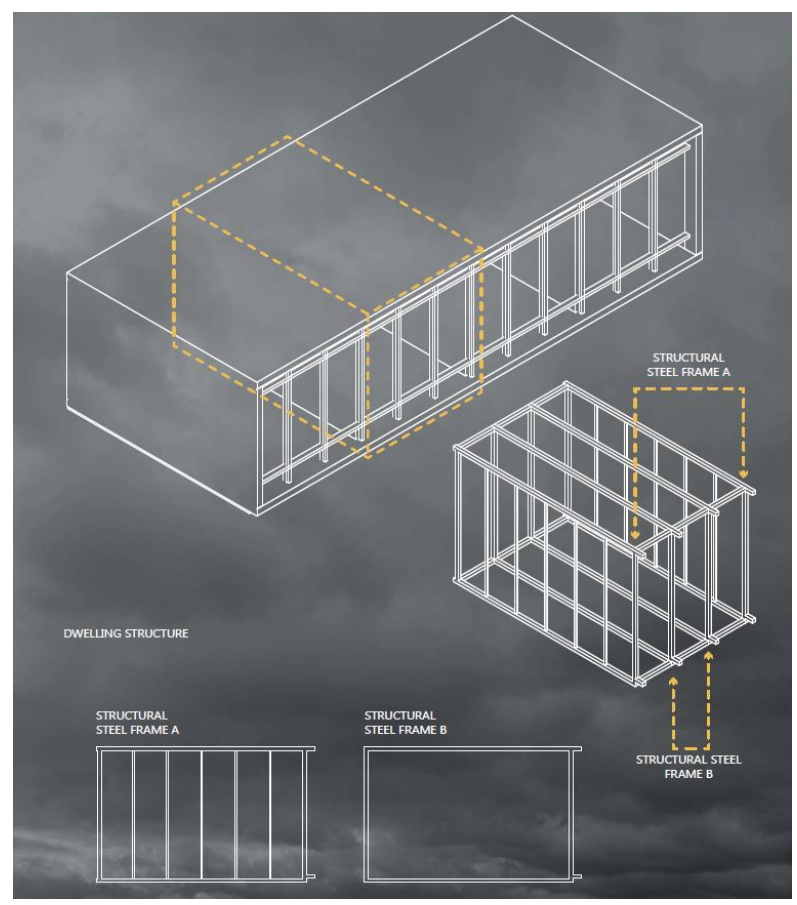

Figure 48. Dwelling Structure 


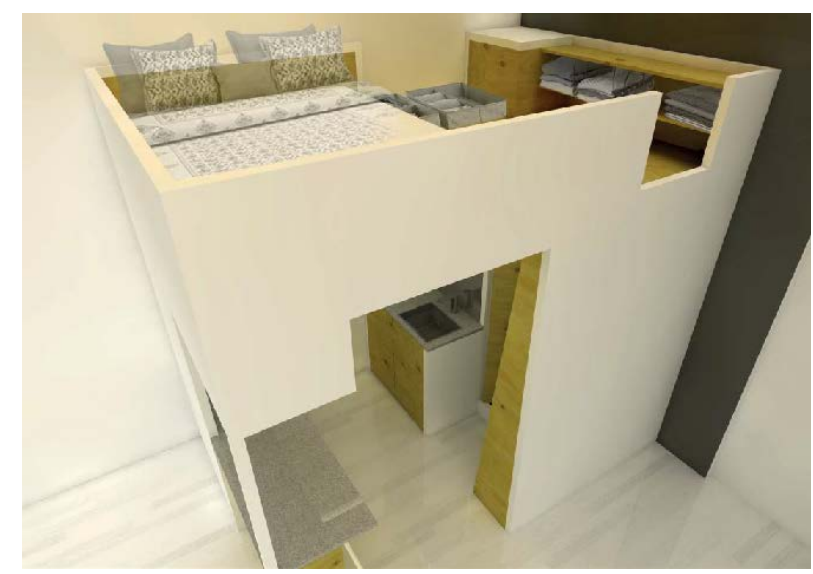

Figure 49. Internal Render 1

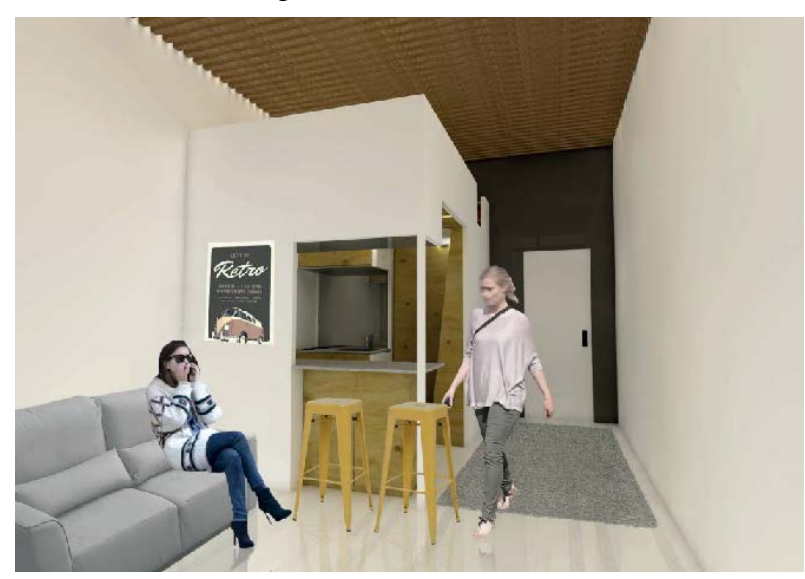

Figure 51. Internal Render 3

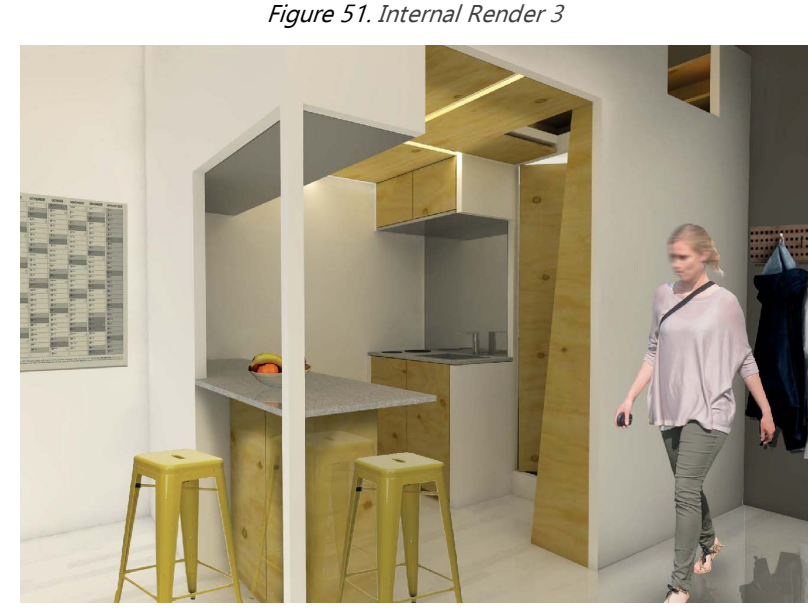

Figure 53. Internal Render 5

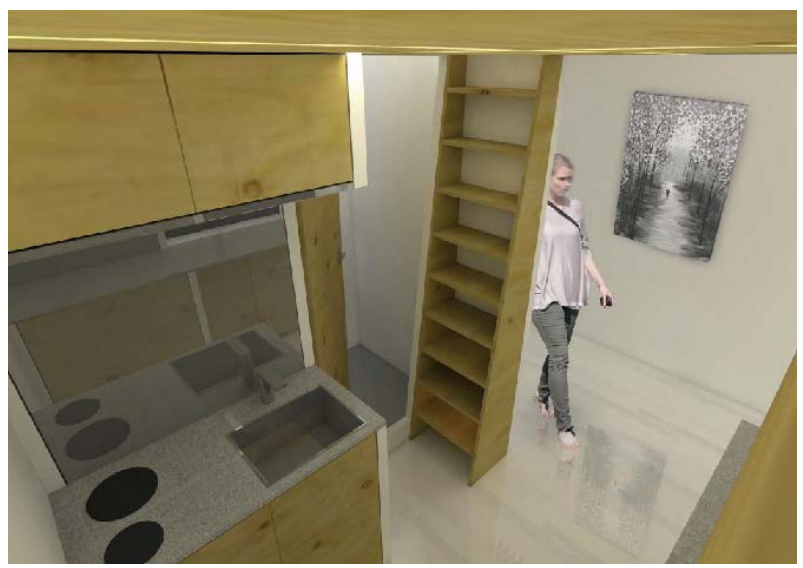

Figure 50. Internal Render 2

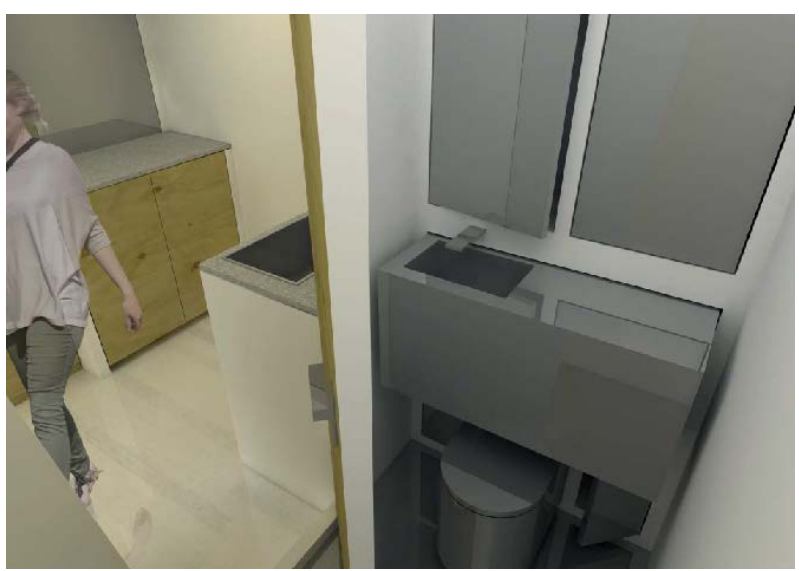

Figure 52. Internal Render 4 


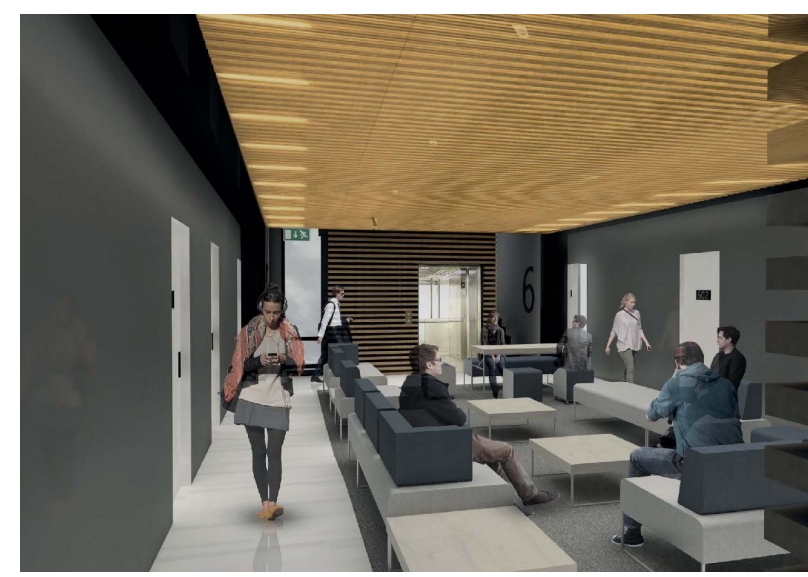

Figure 54. Communal Render

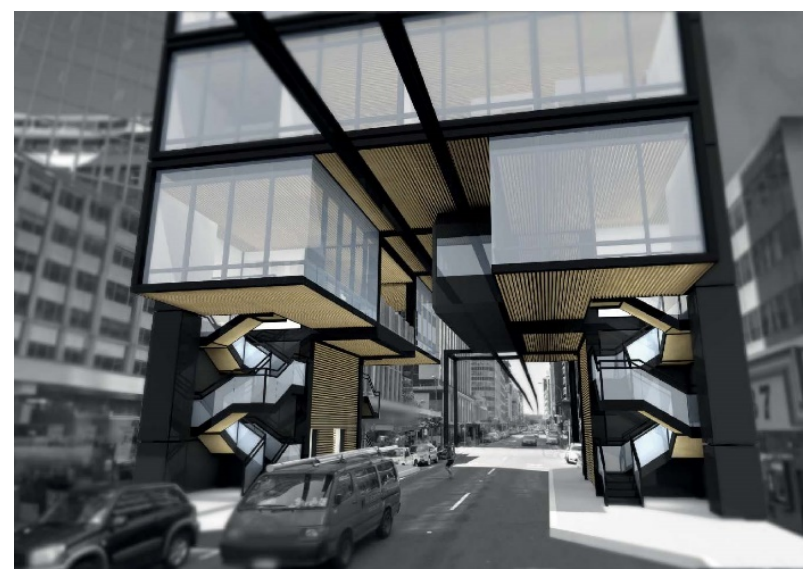

Figure 55. Station Render

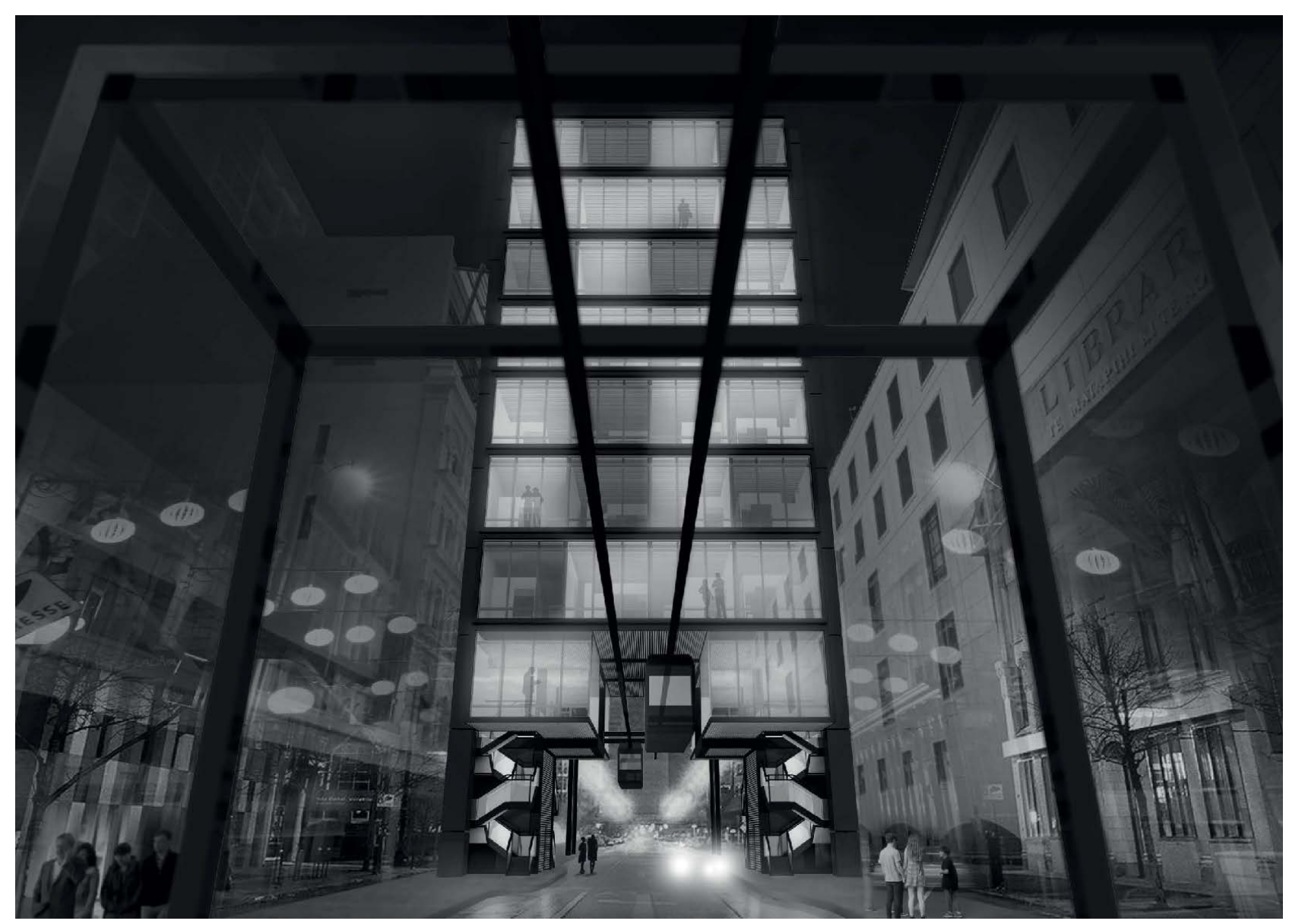

Figure 56. External Render 


\section{Chapter 8 - Conclusions and Critical Reflection}

The product of this research portfolio is a detailed design that was not fully developed, which would have been extensively experimented on if the project were to have continued. The design feels well resolved and exhibits a good insight into how the design could look if developed further. Because of the short timeframe and lack of resources this project suffered, which is because of the attempt at a large scope from the beginning and the alteration of project programme in the early stages, although for the better.

This research portfolio has many successful aspects, many aspects that require improvement and some aspects that are missing. Upliving - student accommodation is a very process-based research portfolio, which, as this project is one of the last opportunities to explore design with unlimited/self-created parameters, it was a good way of discovering different design methodologies and generating new ideas. Model making is the main system used for design in this project; it was a great way when used iteratively to design from preliminary through to developed design. If used in subsequent stages of the project, instead of primarily the concept and developed design stages, it could have made the projects detailed design section much stronger. The earlier stages of the project used iterative design very powerfully, providing logic and reason at every design decision, however that fell short as the project moved into the later stages. This was because of the small nature of this research portfolio.

Due to the extensive work in the justification of each stage of the project, until the developed design stage, the developed design stage became secondary, causing the detailed design to be a larger challenge than it might have been. If this project were to be extended into the future, the developed design stage would be elaborated on with the same diligence that was exhibited earlier in the project, to thoroughly link the project elements together, as well as link them back to the initial context and programme analysis. It was found that through the concept design stage the project diverted from those initial steps and lost its connection to the client and the site, which initially was a major driver for the project.

If it were to be continued or, restarted, the process would be much the same, yet would include a much more in-depth detailed design stage utilising the same process exhibited throughout. The additional iterative design stage would be to unify the four components of the design/design process to remove the separation and individuality of each element. As it stands, this research portfolio could have become four different research portfolios as there was a large scope with many aspects. In reflection, to improve this project, either of the following could be implemented: a design focussed on a single of the four components, a unity from an additional design stage allowing more focus on the detailed design stage, or a reduction of the design scope (for example the removal of the connection aspect of the project).

The project's success at answering the initial research question (How can student accommodation help to combat Wellington City's struggle, with limited urban space and the need for urban development?) can be 
defined by its success in completing the goals set out at the beginning. This research portfolio achieves the majority of the initial set out goals, discussed in the introduction. It successfully:

- Accommodates students in a futuristic condition

- Maintains a minimal building footprint

- Has minimal circulation, in the form of stairwells and communal spaces

- Provides a flexible space that can change to suit requirements

- Maintains a simple structure for rapid construction

- Provides active communal spaces for student interactions

- Establishes links between university campuses and other Wellington amenities

- Effectively uses the space above roads, which would otherwise be empty

The goal that was not fully completed was the effective use of multiple underutilised spaces, however, this goal was altered early on to give the project a stronger direction.

With a project of this scale, some challenges arose throughout the process. Designing for one demographic of people proved challenging because of assumptions that were made. Because of the single demographic, the assumptions may not represent the entire student population. Customisation was a large driver and became challenging in the attempt to customise the design for many different sites, to compromise, a single site was chosen. Therefore the only customisation in the design became the accommodation units, which relied on the occupant of the space. Another challenge was transforming a theoretical idea, from models and drawings into a detailed design, which is the reason for this research portfolio experiment.

To conclude, 'Upliving - Student Accommodation' was a successful exercise for educational purposes and highlighted many effective design methods to be used in the future, as well as effective critique and reflection invaluable for future practices. 


\section{Chapter 9 - Bibliography}

\section{I - TEXTS}

Descartes, Rene (2004) [1637]. A Discourse on Method: Meditations and Principles. Translated by Veitch, John. London: Orion Publishing Group. p. 15.

Montiglio, S. (2005). Wandering in Ancient Greek Culture. Chicago and London: University of Chicago Press.

Quinn, D. (2000). Beyond Civilization. New York: Three Rivers Press.

Smith, A. (2013). In Defence of Homelessness. The Journal of Value Inquiry, 48(1), pp 33-51. doi:10.1007/s10790-013-9405-x

\section{II - WEBSITES}

Chalcraft, E. (2013). Excrescent Utopia by Milo Ayden De Luca - Dezeen. Retrieved from: https://www.dezeen.com/2013/01/17/excrescent-utopia-parasitic-architecture-for-homeless-bymilo-ayden-de-luca/

Chin, Andrea. tengbom architects design a smart student flat - designboom. Retrieved from: https://www.designboom.com/architecture/tengbom-architects-design-a-smart-student-flat/

Dukehart, C. (2015). One Girl's Tunnel Life: Under the Streets of Bucharest - National Geographic. Retrieved from: http://proof.nationalgeographic

Frearson, Amy. (2011). Sleepbox 01 by Arch Group - DEZEEN. Retrieved from: https://www.dezeen.com/2011/09/12/sleepbox-01-by-arch-group/

Illum-Davis, D. (2012). Rough - Housing the Homeless in Westminster. (Master's Thesis, Aarhus School of Architecture). Retrieved from: https://futuresplus.net/2012/12/10/rough-housing-the-homeless-inwestminster-daniel-illum-davis/

Koglek, Nuno. (2013). Introduction to Frank Lloyd Wright and Broadacre City - UTOPICS. Retrieved from: http://utopicus2013.blogspot.co.nz/2013/06/introduction-to-frank-lloyd-wright-and.html

Malka, S. (2014). Stéphane Malka visualizes P9 ghetto-mobile as a nomadic micro-city - Designboom. Retrieved from: http://www.designboom.com/architecture/stephane-malka-p9-ghetto-mobilepont9-bridge-paris-12-09-2014/.com/2015/06/17/one-girls-tunnel-life-under-the-surface-inbucharest/

Mastin, L. (2008). The Basics of Philosophy - Cynicism. Retrieved from: http://www.philosophybasics.com/movements_cynicism.html

Unknown Author. (2016). A Plan for Tokyo 1960 / Kenzo Tange - ARCHEYES, Retrieved from: http://archeyes.com/plan-tokyo-1960-kenzo-tange/.

Unknown Author. (2015). Nakagin Capsule Tower - ArchiTravel, Retrieved from: http://www.architravel.com/architravel/building/nakagin-capsule-tower/ 
Wodiczko, Krzysztof. (1989). Homeless vehicle project - MUZEUM. Retrieved from: https://artmuseum.pl/en/filmoteka/praca/wodiczko-krzysztof-homeless-vehicle-project

\section{III - FIGURES}

Figure 01. Joshua Roberts, Methodology Diagram, 2017, New Zealand Figure 02. Joshua Roberts, Design Components, 2017, New Zealand Figure 03. Joshua Roberts, Amenity Concept Process, 2017, New Zealand Figure 04. Joshua Roberts, Dwelling Concept Process, 2017, New Zealand Figure 05. Joshua Roberts, Structure Concept Process, 2017, New Zealand Figure 06. Joshua Roberts, Connection Concept Process, 2017, New Zealand

Figure 07. Google Maps, "Cranes on Queens Wharf,"(2017), https://www.google.co.nz/maps/@$41.2788659,174.7849135,378 \mathrm{~m} /$ data $=! 3 \mathrm{~m} 1 ! 1 \mathrm{e} 3$

Figure 08. Google Maps, "Car Park on Bond Street," (2017), https://www.google.co.nz/maps/place/Bond+St, +Wellington+6011/@41.2889058,174.7752644,151m/data=!3m1!1e3!4m5!3m4!1s0x6d38afd65f63c0af:0x4bff788e2e934a7 $2 ! 8 m 2 ! 3 d-41.2894568 ! 4 d 174.7759977$

Figure 09. Google Maps, "Farmers Lane," (2017), https://www.google.co.nz/maps/place/Farmers+Ln,+Wellington,+6011/@41.2815885,174.7735973,741m/data=!3m2!1e3!4b1!4m5!3m4!1s0x6d38ae2ae0607d65:0xbffd894b04 $61 \mathrm{ca} 87 ! 8 m 2 ! 3 d-41.2815885 ! 4 d 174.7757913$

Figure 10. Joshua Roberts, Car Park on The Terrace, 2015, New Zealand

Figure 11. Google Maps, "Post Office Square,"(2017), https://www.google.co.nz/maps/place/Post+Office+Square,+Wellington,+6011/@41.2850307,174.7751052,740m/data =!3m2!1e3!4b1!4m5!3m4!1s0x6d38afd48da807bd:0xd7cda04293 04dab4!8m2!3d-41.2850307!4d174.7772992

Figure 12. Joshua Roberts, Site Conditions, 2017, New Zealand

Figure 13. Joshua Roberts, Photo Sketch Experiment, 2017, New Zealand Figure 14. Joshua Roberts, Site and Context Analysis, 2017, New Zealand Figure 15. Joshua Roberts, Transport Route and Nodes, 2017, New Zealand Figure 16. Joshua Roberts, Homelessness Diagram, 2017, New Zealand Figure 17. Joshua Roberts, Client Requirements, 2017, New Zealand Figure 18. Joshua Roberts, Design Components, 2017, New Zealand Figure 19. Joshua Roberts, Amenity Module Study, 2017, New Zealand Figure 20. Joshua Roberts, Amenity Module Comparison, 2017, New Zealand 
Figure 21. Daniel Illum-Davis, "Rough - Housing the Homeless in Westminster," (2012), https://futuresplus.net/2012/12/10/rough-housing-the-homeless-in-westminster-daniel-illum-davis/

Figure 22. Milo De Luca, "Excrescent Utopia," (2013), http://www.miloaydendeluca.com/excrescentutopia/image/1

Figure 23. Milo De Luca, "Excrescent Utopia," (2013), http://www.miloaydendeluca.com/excrescentutopia/image/1

Figure 24. Stéphane Malka, "PONT9," (2014), http://www.designboom.com/architecture/stephane-malka-p9ghetto-mobile-pont9-bridge-paris-12-09-2014/

Figure 25. "Nakagin Capsule Tower," (2015), http://www.architravel.com/architravel/building/nakagincapsule-tower/

Figure 26. Joshua Roberts, The Halfway Neighbourhood, 2016, New Zealand

Figure 27. Frank Lloyd Wright, "Broadacre City," UTOPICUS, (2013), http://utopicus2013.blogspot.co.nz/2013/06/introduction-to-frank-lloyd-wright-and.html

Figure 28. Kenzo Tange, "A Plan for Tokyo," ARCHEYES, (2016), http://archeyes.com/plan-tokyo-1960-kenzotange/.

Figure 29. Joshua Roberts, Precedent Matrix 1, 2017, New Zealand

Figure 30. Joshua Roberts, Precedent Matrix 2, 2017, New Zealand

Figure 31. Joshua Roberts, Precedent Matrix 3, 2017, New Zealand

Figure 32. Joshua Roberts, Precedent Comparison, 2017, New Zealand

Figure 33. Joshua Roberts, New York Trolley, 2017, New Zealand

Figure 34. Joshua Roberts, Student Flat, 2017, New Zealand

Figure 35. Joshua Roberts, Sleepbox, 2017, New Zealand

Figure 36. Joshua Roberts, Preliminary Design Collages, 2017, New Zealand

Figure 37. Joshua Roberts, Dwelling Model Concepts, 2017, New Zealand

Figure 38. Joshua Roberts, Design Components, 2017, New Zealand

Figure 39. Joshua Roberts, Amenity Development Process, 2017, New Zealand

Figure 40. Joshua Roberts, Dwelling Concept Process, 2017, New Zealand

Figure 41. Joshua Roberts, Structure Development Process, 2017, New Zealand

Figure 42. Joshua Roberts, Connection Development Process, 2017, New Zealand

Figure 43. Joshua Roberts, WC Design, 2017, New Zealand

Figure 44. Joshua Roberts, Amenity Module Design, 2017, New Zealand

Figure 45. Joshua Roberts, Structure Model Concepts 1, 2017, New Zealand

Figure 46. Joshua Roberts, Structure Mode/ Concepts 2, 2017, New Zealand

Figure 47. Joshua Roberts, Amenity Customisation Diagram, 2017, New Zealand 
Figure 48. Joshua Roberts, Dwelling Structure, 2017, New Zealand Figure 49. Joshua Roberts, Internal Render 1, 2017, New Zealand Figure 50. Joshua Roberts, Internal Render 2, 2017, New Zealand Figure 51. Joshua Roberts, Internal Render 3, 2017, New Zealand Figure 52. Joshua Roberts, Internal Render 4, 2017, New Zealand Figure 53. Joshua Roberts, Internal Render 5, 2017, New Zealand Figure 54. Joshua Roberts, Communal Render, 2017, New Zealand Figure 55. Joshua Roberts, Station Render, 2017, New Zealand Figure 56. Joshua Roberts, External Render, 2017, New Zealand 
Upliving - Student Accommodation 